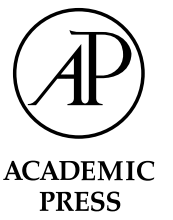

\title{
Sensitivity to local sentence context information in lexical ambiguity resolution: Evidence from left- and right-hemisphere-damaged individuals ${ }^{\text {it }}$
}

\author{
Christopher M. Grindrod* and Shari R. Baum \\ School of Communication Sciences and Disorders and the Centre for Research on Language, Mind and Brain, McGill University, \\ 1266 Pine Avenue West, Montreal, Que., Canada H3G 1 A8
}

Accepted 5 March 2003

\begin{abstract}
Using a cross-modal semantic priming paradigm, the present study investigated the ability of left-hemisphere-damaged (LHD) nonfluent aphasic, right-hemisphere-damaged (RHD) and non-brain-damaged (NBD) control subjects to use local sentence context information to resolve lexically ambiguous words. Critical sentences were manipulated such that they were either unbiased, or biased toward one of two meanings of sentence-final equibiased ambiguous words. Sentence primes were presented auditorily, followed after a short $(0 \mathrm{~ms})$ or long $(750 \mathrm{~ms})$ interstimulus interval (ISI) by the presentation of a first- or second-meaning related visual target, on which subjects made a lexical decision. At the short ISI, neither patient group appeared to be influenced by context, in sharp contrast to the performance of the NBD control subjects. LHD nonfluent aphasic subjects activated both meanings of ambiguous words regardless of context, whereas RHD subjects activated only the first meaning in unbiased and second-meaning biased contexts. At the long ISI, LHD nonfluent aphasic subjects failed to show evidence of activation of either meaning, while RHD individuals activated first meanings in unbiased contexts and contextually appropriate meanings in second-meaning biased contexts. These findings suggest that both left ( $\mathrm{LH})$ and right hemisphere (RH) damage lead to deficits in using local contextual information to complete the process of ambiguity resolution. LH damage seems to spare initial access to word meanings, but initially impairs the ability to use context and results in a faster than normal decay of lexical activation. RH damage appears to initially disrupt access to context, resulting in an over-reliance on frequency in the activation of ambiguous word meanings.
\end{abstract}

(C) 2003 Elsevier Science (USA). All rights reserved.

Keywords: Lexical ambiguity resolution; Semantic priming; Context effects; Nonfluent aphasia; Right hemisphere damage; Laterality

\section{Introduction}

While the role of the left hemisphere (LH) in language comprehension is well established, it is becoming less controversial to suggest a parallel role for the right hemisphere (RH), especially within the domain of lexical-semantic processing (Chiarello, 1998; Joanette, Goulet, \& Hannequin, 1990). Evidence derived from both

\footnotetext{
The research reported here forms part of a doctoral dissertation by the first author submitted to McGill University. This research was supported by a studentship from the Faculty of Medicine, McGill University and by a Doctoral Research Award from the Canadian Institutes of Health Research (200010MDR-87078) to the first author and by a grant from the Fonds pour la Formation de Chercheurs et l'Aide à la Recherche to the second author. A portion of the preliminary data from this study was presented at TENNET XII, Montreal, Que., June 21-23, 2001 and at the 40th annual meeting of the Academy of Aphasia, New York, NY, October 20-22, 2002. The authors wish to thank Emma Duerden for her invaluable assistance in data collection, Anne Grindrod for her assistance in collecting the data for the bias norming test and Wendi Aasland for recording the stimuli. I would also like to thank the other members of my dissertation committee, Marc Pell and Carol Leonard, for their insightful comments and general encouragement throughout the completion of this study. Finally, many thanks go to the patients for their continued interest and participation and to the local hospitals and rehabilitation centers for their efforts in identifying and recruiting participants.

${ }^{*}$ Corresponding author. Fax: +514-398-8123.

E-mail address: christopher.grindrod@mail.mcgill.ca (C.M. Grindrod).
} 
clinical populations and studies of neurologically intact individuals suggests that the $\mathrm{RH}$ not only contributes to the activation of peripheral aspects of word meanings, but is also necessary for revising initial interpretations which turn out to be incorrect (Beeman, 1993, 1998; Brownell, Potter, Michelow, \& Gardner, 1984; Chiarello, 1998; Rodel, Cook, Regard, \& Landis, 1992; Titone, 1998). These aspects of RH language comprehension are of particular importance in the processing of lexically ambiguous words (e.g., bank: $a$ financial institution and the side of a river). Indeed, a number of recent studies have argued for a unique contribution of the RH to lexical ambiguity resolution (Faust \& Chiarello, 1998b; Faust \& Gernsbacher, 1996). Moreover, in addition to a specific role for the $\mathrm{RH}$, these studies have also argued that the process of ambiguity resolution requires the intact functioning of both cerebral hemispheres.

One aspect of ambiguity resolution about which very little is known is the extent to which each hemisphere uses context to guide the resolution process. The results of numerous psycholinguistic studies have shown that context plays a significant role in the processing of lexically ambiguous words (Binder \& Rayner, 1998; Dopkins, Morris, \& Rayner, 1992; Duffy, Morris, \& Rayner, 1988; Martin, Vu, Kellas, \& Metcalf, 1999; Paul, Kellas, Martin, \& Clark, 1992; Rayner, Pacht, \& Duffy, 1994; Simpson, 1981, 1984; Simpson \& Krueger, 1991; Tabossi, 1988; Tabossi, Colombo, \& Job, 1987; Van Petten \& Kutas, 1987; Vu, Kellas, \& Paul, 1998, 2000). Thus, there is abundant evidence that contextual information is available during on-line language comprehension to guide the resolution process, though some debate does remain as to the point in time at which this information comes into play, either at an early lexical access stage or at a later post-access stage (for a review, see Simpson, 1984, 1994). A logical next question is to ask how contextual information is used by the two hemispheres in ambiguity resolution. The present experiment attempts to address this question by examining the effect of left and right hemisphere brain damage on the ability to use context in resolving lexically ambiguous words. In investigating the effects of focal brain damage on ambiguity resolution, this research has clear implications for models of normal language comprehension, in terms of how activation of ambiguous word meanings proceeds in the cerebral hemispheres and how initial lexical access is affected by the presence of a sentence context.

\subsection{Sentence context effects in lexical ambiguity resolu- tion}

As noted above, the role of context in lexical ambiguity resolution has received a great deal of attention in the psycholinguistic literature. The goal of this research has been to establish whether or not context can con- strain processing to only the meaning of the ambiguous word which is appropriate to the context. Support for context-sensitive ambiguity resolution has come from studies conducted by Tabossi and colleagues, among others (Tabossi, 1988; Tabossi et al., 1987). Using a cross-modal semantic priming paradigm, Tabossi et al. (1987) had subjects make lexical decisions on targets related to either dominant- or subordinate-biased sentences containing lexically ambiguous words. Crucially, the sentences were constructed in such a way as to make salient the most characteristic features of either the dominant or subordinate meaning. The most critical finding of this study was that after presentation of a dominant-biased sentence, only targets representing semantic features of the dominant meaning were primed (e.g., only the target safe (and not red) was primed by the sentence The violent hurricane did not damage the ships that were in the PORT, one of the best equipped along the coast). This finding was replicated by Tabossi (1988), who once again showed that the dominant meaning of an ambiguous word can be selectively activated by a context that is sufficiently constraining (i.e., one that activates a characteristic feature of the appropriate meaning).

Related to these studies, Paul et al. (1992) have provided further evidence for the sensitivity of initial meaning activation to context, using a modified Stroop task. They found that after reading dominant- and subordinate-biased sentences ending in ambiguous words (e.g., They need to use a BAT), subjects' colornaming latencies were longer for contextually appropriate targets than for inappropriate targets. This result was interpreted as evidence that the appropriate targets received greater activation from the context and as a result, interfered more with naming the color of the target. Moreover, not only was this effect observed for high-salient targets (i.e., those generated by $70 \%$ of subjects in a pretest), such as hit, but it was also found for low-salient targets (i.e., those generated by less than $5 \%$ of subjects), such as catcher, suggesting that a broad range of semantic features was activated by the ambiguous words in the particular context. Overall, the findings of Paul et al. (1992), combined with those of Tabossi (1988; Tabossi et al., 1987), provide strong support for the position that context can have immediate effects on the activation of ambiguous word meanings.

In an effort to further examine the extent to which context influences initial activation of ambiguous word meanings, a number of studies have not only manipulated the type of biasing context (i.e., dominant or subordinate), but also the strength of the context (Binder \& Rayner, 1998; Martin et al., 1999; Rayner et al., 1994; Simpson, 1981; Vu et al., 1998, 2000). In one study, Martin et al. (1999) found that when the context was weakly biased toward the subordinate meaning of 
an ambiguous word, both meanings were activated. This is, in fact, similar to what has been shown in an ambiguous or unbiased context (Simpson \& Krueger, 1991). In contrast, when the context was weakly biased toward the dominant meaning, only that meaning was activated, indicating that meaning frequency also played a role. When the context was strongly biased, only contextually appropriate meanings of the ambiguous word were activated, whether dominant or subordinate (see also Simpson, 1981). In addition to these findings, Martin et al. (1999) also observed a strong relationship between processing time and meaning frequency in weakly biased contexts; reading times for ambiguous words in weakly biased subordinate contexts increased as the frequency of the dominant meaning increased, due to the subordinate meaning requiring more processing time to reach its threshold of activation. In contrast, no such relationship was found in strongly biased contexts and processing of the ambiguous words was not affected by meaning frequency. This pattern of results has been found not only using local (i.e., singlesentence) contexts, in which the specificity of subject nouns or main verbs is manipulated in order to produce varying degrees of contextual strength (Vu et al., 1998), but has also been observed using global (i.e., two or more sentence) contexts, where the biasing information is not contained within the same sentence as the ambiguous word (Martin et al., 1999; Vu et al., 2000). In sum, findings of the above-mentioned studies provide strong evidence that a biasing context can lead to selective activation of the contextually appropriate meaning of an ambiguous word under certain conditions. Moreover, they also argue that context effects may vary depending on the degree to which the context is biased (i.e., on the strength of the context).

\subsection{Hemispheric differences in resolving lexical ambiguity}

Insight into the role of the cerebral hemispheres in ambiguity resolution has come from a number of semantic priming studies using the divided visual field technique (Atchley, Burgess, Audet, \& Arambel, 1996, 1999; Burgess \& Simpson, 1988; Collins, 2002; Coney \& Evans, 2000; Faust \& Chiarello, 1998b; Faust \& Gernsbacher, 1996; Hasbrooke \& Chiarello, 1998; Titone, 1998). This technique allows for inferences to be made about $\mathrm{LH}$ and $\mathrm{RH}$ processing because of the brief, lateralized presentation of stimuli (to either the left or right half of the visual field). The nature of the primary visual system is such that stimuli presented to the right half of the visual field (or right visual hemifield) are initially projected, through the optic nerves, to the left cerebral cortex and vice versa. Thus, stimuli presented to the right visual hemifield (RVF) are assumed to reflect LH processing, whereas stimuli presented to the left visual hemifield (LVF) are assumed to reflect RH pro- cessing. Findings of these studies have contributed to our understanding of how activation of ambiguous word meanings proceeds in the left and right cerebral hemispheres.

Before addressing the role of context, it is important to first establish how activation of ambiguous word meanings proceeds in the hemispheres when no context is provided (Atchley et al., 1996, 1999; Burgess \& Simpson, 1988; Collins, 2002; Hasbrooke \& Chiarello, 1998). A study by Burgess and Simpson (1988) speaks directly to this issue. In this study, subjects were presented with ambiguous word primes (e.g., bank) and after one of two delay intervals [stimulus onset asynchronies (SOA) of either 35 or $750 \mathrm{~ms}$ ], they made lexical decisions on dominant (e.g., money) and subordinatemeaning related targets (e.g., river) presented to the $\mathrm{LVF}$ and $\mathrm{RVF}$. In the $\mathrm{RVF} / \mathrm{LH}$, targets related to the dominant meaning of the ambiguous prime were facilitated at both SOAs. In contrast, when the target was related to the subordinate meaning, facilitation was found only at the short SOA. Burgess and Simpson (1988) argued that these results reflected the fact that in the $\mathrm{LH}$, the focus of attentional resources on the dominant (i.e., more frequent) meaning resulted in maintenance of this meaning over time, and that inhibitory processes acted to suppress the subordinate meaning. Results for the LVF/RH revealed a strikingly different pattern. Targets related to the dominant meaning of the ambiguous prime were once again facilitated at both SOAs (though much less at the long SOA). More importantly, targets related to the subordinate meaning showed no facilitation at the short SOA, but significant facilitation at the long SOA. To account for these results, Burgess and Simpson (1988) proposed that the decay of subordinate meanings in the $\mathrm{LH}$ was matched by a corresponding increase in activation for those meanings in the RH. Thus, the RH served to maintain alternative meanings in case they were later required.

Though the study of Burgess and Simpson (1988) was conducted with no context, similar results have also been found in studies using sentence contexts (Coney \& Evans, 2000; Faust \& Chiarello, 1998b; Faust \& Gernsbacher, 1996; Titone, 1998). For example, Faust and Gernsbacher (1996) had subjects read centrally presented sentences (presented one word at a time) ending in an ambiguous (e.g., He dug with the SPADE) or unambiguous word (e.g., He dug with the SHOVEL), followed by laterally presented targets related to the contextually inappropriate meaning (e.g., ace). Subjects were to judge whether the target was related to the meaning of the preceding sentence. Interference from the contextually inappropriate meaning was indicated by longer reaction times to reject targets after ambiguous versus unambiguous sentences. Both a short $(100 \mathrm{~ms})$ and long $(1000 \mathrm{~ms}) \mathrm{SOA}$ were used to examine potential decreases in interference (i.e., suppression of 
inappropriate meanings) over time. Results showed that at the short SOA, the contextually inappropriate meaning was activated in both the RVF/LH and LVF/ $\mathrm{RH}$. In contrast, at the long SOA, the contextually inappropriate meaning was suppressed in the $\mathrm{RVF} / \mathrm{LH}$, but not in the LVF/RH. These results demonstrate that the $\mathrm{LH}$ is able to suppress inappropriate meanings over time, whereas the RH provides little suppression (i.e., it maintains inappropriate meanings).

The role of the two hemispheres in ambiguity resolution during sentence comprehension was further investigated by Faust and Chiarello (1998b). They presented subjects with sentences biasing either the dominant (e.g., He could not wait for even a SECOND) or subordinate meaning (e.g., She stood in line and was $S E C O N D$ ) of a sentence-final ambiguous word. Targets for lexical decision responses, presented at a $900 \mathrm{~ms}$ SOA, were either related to the dominant meaning (e.g., time), to the subordinate meaning (e.g., number) or were unrelated control words (e.g., sound). Results revealed that priming in the $\mathrm{RVF} / \mathrm{LH}$ was restricted to only those targets that were consistent with the context (i.e., dominant-biased sentences primed dominant-related targets and subordinate-biased sentences primed subordinaterelated targets). In contrast, priming in the LVF/RH was observed for both related targets, regardless of whether or not they were consistent with the context. Thus, in agreement with Faust and Gernsbacher's (1996) results at the long SOA, selection of the contextually appropriate meaning was carried out in the $\mathrm{LH}$, while the RH maintained alternative meanings, even those that were contextually inappropriate.

In yet another study, Titone (1998) also looked at sensitivity of the two hemispheres to context, using a cross-modal lexical decision task. In this study, sentence primes always ended in ambiguous words and targetspresented at a $0 \mathrm{~ms}$ interstimulus interval (ISI) - were related to either the dominant or subordinate meaning. Sentence contexts were manipulated to examine the effect of (1) a neutral (i.e., unbiased) context (e.g., They really liked the $B A L L)$, (2) a context biasing central semantic features of the subordinate meaning (e.g., $B e$ cause it featured a great orchestra, they really liked the $B A L L$ ), and (3) a context biasing peripheral semantic features of the subordinate meaning (e.g., Because it lasted the entire night, they really liked the $B A L L$ ). In neutral contexts, priming effects were obtained in both the $\mathrm{RVF} / \mathrm{LH}$ and LVF/RH for the dominant meaning only. In contexts biasing central semantic features of the subordinate meaning, priming effects were obtained for dominant and subordinate meanings in both the RVF/ $\mathrm{LH}$ and $\mathrm{LVF} / \mathrm{RH}$. In contexts biasing peripheral semantic features of the subordinate meaning, priming effects for the dominant meaning were only obtained in the $\mathrm{RVF} / \mathrm{LH}$, while priming effects for the subordinate meaning were only obtained in the LVF/RH. While these results support the hypothesis that the two hemispheres are differentially sensitive to biasing contexts that emphasize different types of semantic features, they are inconsistent with other studies, in suggesting that only inappropriate meanings are activated in the $\mathrm{LH}$, whereas only appropriate meanings are activated in the RH (cf. Faust \& Chiarello, 1998b; Faust \& Gernsbacher, 1996). However, this lack of agreement is less surprising, given that Titone (1998) focused solely on ambiguity resolution in subordinate-meaning biased contexts.

In sum, the majority of studies outlined in this section support the position that both hemispheres play a role in the ambiguity resolution process. Moreover, they also suggest that ambiguous word meanings may be processed in a very different manner in the left and right cerebral hemispheres. All meanings of an ambiguous word appear to be initially activated in both hemispheres. Only after this initial exhaustive activation pattern does processing in the hemispheres seem to diverge. While the LH quickly selects the contextually appropriate meaning over time, the $\mathrm{RH}$ seems to maintain alternative, contextually inappropriate meanings, perhaps in case a revision of the initial interpretation is required at a later point in time (Beeman, 1993, 1998; Chiarello, 1998). Additional evidence concerning the role of each hemisphere in lexical ambiguity resolution comes from the study of focally brain-damaged patients. It is to a summary of this literature that we now turn.

\subsection{Ambiguity resolution in left-hemisphere-damaged nonfluent aphasic individuals}

A number of studies of left-hemisphere-damaged (LHD) nonfluent Broca's aphasic patients have examined their ability to extract information from context in order to comprehend sentences containing ambiguous words (Hagoort, 1990; Prather, Love, Finkel, \& Zurif, 1994; Swaab, Brown, \& Hagoort, 1998; Swinney, Zurif, \& Nicol, 1989, 2000). In particular, these studies have sought to determine whether LH damage causing nonfluent aphasia affects the ability to access the dominant and subordinate meanings of ambiguous words (i.e., lexical access processes) or the ability to use the context in which the ambiguous word appears to select the appropriate meaning (i.e., selection processes).

Using a cross-modal lexical decision task, Swinney et al. (1989) examined the effect of a biasing sentence context on the ability of LHD aphasic patients to perform lexical ambiguity resolution. In this study, Broca's and Wernicke's aphasic patients listened to sentences (e.g., The gardener was responsible for watering every PLANT on the enormous estate) and made lexical decisions on visual targets (e.g., treelfactory) presented at the offset of the ambiguity (i.e., mid-sentence). Contexts 
were manipulated such that half the sentences were biased toward the dominant meaning of the ambiguous word and the other half toward the subordinate meaning. Similar to the results of the non-brain-damaged (NBD) control subjects, Wernicke's aphasic patients showed facilitation for both dominant and subordinate meanings of the ambiguous words regardless of the preceding context. In contrast, Broca's aphasic patients showed facilitation only for the dominant (i.e., most frequent) meaning of the ambiguous word, irrespective of the preceding context. From this result, Swinney et al. (1989) concluded that Broca's aphasic patients either failed to exhaustively access word meanings (i.e., they did not access the subordinate meaning) or that the lexical search module operated on a slower than normal rise time for these individuals, such that only the dominant meaning could be accessed within the specific time frame (i.e., $0 \mathrm{~ms}$ ISI) examined.

To further test the second (slowed activation) hypothesis, Prather et al. (1994) conducted a study using the same cross-modal priming paradigm, with two critical modifications: a $1500 \mathrm{~ms}$ ISI was used and only dominant-biased sentences were presented. Even given this extra processing time, Broca's aphasic patients still only showed facilitation for targets related to the dominant meaning of the ambiguous word (i.e., the subordinate meaning was not facilitated in contexts biased toward the dominant meaning). That Broca's aphasic patients were sensitive to the dominant-biased context is consistent with studies of normal young subjects, who also show selective facilitation of the contextually appropriate dominant meaning in these contexts (Paul et al., 1992; Simpson \& Krueger, 1991; Tabossi et al., 1987; Vu et al., 1998, 2000). Moreover, Prather et al. (1994) argue that this finding could be a consequence of slowed lexical activation in Broca's aphasic patients, where a slower than normal rise time in activation allowed context to penetrate the lexical access module (Prather, Zurif, Stern, \& Rosen, 1992, 1997). However, given that a time interval of $1500 \mathrm{~ms}$ is more than sufficient for the dominant meaning to be integrated into the context and for the subordinate meaning to decay or to be suppressed, no activation of the subordinate meaning was to be expected in this study. Therefore, the findings of Prather et al. (1994) are inconclusive with respect to the activation of subordinate meanings of ambiguous words.

Though the above-mentioned studies have argued that slowed activation is the cause of nonfluent Broca's aphasic patients' difficulty in resolving lexically ambiguous words (Prather et al., 1994; Swinney et al., 1989), other studies have suggested that their difficulty stems more from a deficit in integrating meanings into context in order to select which meaning of the ambiguous word is appropriate (Hagoort, 1990; Swaab et al., 1998). One such study is that of Swaab et al. (1998), who presented
Broca's aphasic patients with lexical ambiguities in three different sentence contexts while event-related potentials were recorded. Experimental stimuli were constructed such that each sentence ended in an ambiguous word (e.g., bank) and was followed by a target related to one of its meanings (e.g., river). In the concordant condition, the sentence biased the target-related meaning (e.g., The man planted a tree on the BANK), whereas in the discordant condition, the sentence biased the alternative meaning (e.g., The man made a phone call to the BANK). In the control condition, the sentence was unrelated to the target (e.g., The boy petted the dog on its head). The activational status of the ambiguous words was inferred from the amplitude of the N400 to the targets at two ISIs (100 and $1250 \mathrm{~ms}$ ). Previous studies have shown that context can modulate the amplitude of the N400, in that it is larger to words which are more difficult to integrate and reduced to words which are easier to integrate into the preceding context (see references cited in Swaab et al., 1998).

As indicated by the results of this study, NBD control subjects were able to activate the contextually appropriate meaning at both ISIs. This was demonstrated by a reduction in the N400 amplitude to targets in the concordant relative to the unrelated and discordant conditions. Because no difference in the pattern of results across ISIs was found, NBD control subjects were assumed to have completed the process of contextual selection in a relatively short period of time. Broca's aphasic patients also showed evidence of activation of the contextually appropriate meaning at the short ISI, in that the N400 amplitude to targets in the concordant condition was reduced relative to unrelated targets. However, in contrast to the NBD control subjects, Broca's aphasic patients were unsuccessful at selecting the appropriate meaning (i.e., the contextually inappropriate meaning was also activated), demonstrated by a significant amplitude difference between the unrelated and discordant conditions. At the long ISI, Broca's aphasic patients did show evidence of contextual selection. Thus, arguing against the slowed activation hypothesis, Swaab et al. (1998) concluded that Broca's aphasic patients were able to access both meanings of the ambiguous word (cf. Prather et al., 1994; Swinney et al., 1989), but that they exhibited a deficit in using the sentence context to select which meaning was appropriate. This deficit may stem from a delay in integrating meanings into an overall message representation of the preceding context (Hagoort, 1990).

In sum, a great deal of evidence supports the position that nonfluent Broca's aphasic patients have a deficit in processing ambiguous words in context. At least three different accounts of their impairment have been suggested in the literature. The 'automatic access' hypothesis claims that automatic access of ambiguous word meanings is impaired (see also Milberg, Blumstein, \& 
Dworetzky, 1987; Swinney et al., 1989). The 'slowed activation' hypothesis maintains that a slowed rise time of lexical activation delays the activation of ambiguous word meanings (Prather et al., 1994; Swinney et al., 1989). Finally, the 'delayed selection/integration' hypothesis argues that automatic access of ambiguous word meanings is intact, with the impairment arising at the level of integrating meanings into context, resulting in delayed contextual selection (Hagoort, 1990; Swaab et al., 1998).

\subsection{Ambiguity resolution in right-hemisphere-damaged individuals}

In addition to studies conducted with nonfluent aphasic patients, other studies have investigated righthemisphere-damaged (RHD) individuals' ability to use context in processing lexically ambiguous words (Fassbinder \& Tompkins, 2001; Tompkins, Baumgaertner, Lehman, \& Fossett, 1997, 2000). Though this is a relatively new line of research, RHD individuals' difficulty in using contextual information has been invoked to explain their deficits in processing other (potentially ambiguous) lexical-semantic and discourse-level phenomena (Cook, 1989; Cook \& Beech, 1990; Gardner, Brownell, Wapner, \& Michelow, 1983). For example, RHD individuals often present with impairments in the comprehension of figurative language, such as metaphors and idioms (Brownell, Simpson, Bihrle, Potter, \& Gardner, 1990; Van Lancker \& Kempler, 1987), in understanding literally false material, such as jokes and indirect requests (Bihrle, Brownell, Powelson, \& Gardner, 1986; Weylman, Brownell, Roman, \& Gardner, 1989), and in drawing inferences from context (Beeman, 1993; Brownell, Potter, Bihrle, \& Gardner, 1986; Lehman \& Tompkins, 2000; Tompkins, Lehman, \& Baumgaertner, 1999). As many of these deficits involve understanding multiple (i.e., competing) interpretations, it is highly likely that RHD individuals may also present with deficits in understanding lexically ambiguous words.

Indeed, a number of recent studies have found this to be the case. In a series of studies conducted by Tompkins and colleagues (Tompkins et al., 1997, 2000), RHD and NBD control subjects were presented with sentences ending in an ambiguous word (e.g., $\mathrm{He}$ landed a PUNCH) and were then asked to judge whether an auditorily presented probe word, representing the unbiased, contextually inappropriate meaning (e.g., soda), fit with the overall sentence meaning. Suppression effectiveness was assessed by comparing reaction times for experimental stimuli to those for control stimuli, created by replacing sentencefinal ambiguous words with unambiguous words (e.g., He landed a $J A B)$. At a short $(175 \mathrm{~ms})$ ISI, both RHD and NBD individuals experienced interference from the contextually inappropriate (i.e., unbiased) meaning of the ambiguous word, whereas at a long $(1000 \mathrm{~ms})$ ISI, interference largely disappeared for the NBD control subjects, but remained for the RHD patients. This finding led the authors to conclude that RHD patients were unable to suppress contextually inappropriate meanings over time. However, Tompkins et al. (2000) also pointed out that the results are consistent with an alternative hypothesis, namely that RHD individuals have a slower rate of lexical-semantic activation which results in later activation and inhibition of inappropriate meanings.

This alternative interpretation was recently tested by Fassbinder and Tompkins (2001), who conducted a follow-up study using the same methodology as outlined above (though with ISIs of 0 and $1000 \mathrm{~ms}$ ). They argued that if RHD individuals have a slower rate of lexicalsemantic activation, interference from inappropriate meanings should increase between the two ISIs. In other words, no interference should occur at the short ISI because inappropriate meanings have not been sufficiently activated, whereas interference should occur at the long ISI because activation of inappropriate meanings has increased over time. This pattern was borne out in the results of the RHD patients, in striking contrast to results of the NBD control subjects, who did not experience any interference from the inappropriate meaning at either ISI, unlike the control subjects in Tompkins et al. (1997, 2000). As such, these findings are consistent with the idea that RH damage produces a slow rate of lexical-semantic activation, but they are not conclusive. Because NBD control subjects also showed no interference at the short ISI, the lack of interference for RHD individuals could simply reflect normal performance (i.e., it may be a function of the normal aging process).

In sum, a number of proposals have been advanced to account for RHD individuals' deficit in ambiguous word processing, with no apparent consensus on the underlying impairment. The 'context deficit' hypothesis, though not specifically tested in studies of ambiguity resolution, seems to suggest that all ambiguous word meanings are activated and maintained, as context cannot be used to provide support for the appropriate meaning (Cook, 1989; Cook \& Beech, 1990). The 'sustained activation' hypothesis posits that activation of ambiguous word meanings is sustained over time, such that inappropriate meanings cannot be inhibited or suppressed (Tompkins et al., 1997, 2000). Finally, the 'slowed activation' hypothesis maintains that lexical activation is slowed, resulting in a slower increase in activation of both meanings of an ambiguous word, as well as a later decrease in activation of these meanings, with the later decrease in activation of the contextually inappropriate meaning leading to prolonged interference (Fassbinder \& Tompkins, 2001). 


\section{The present study}

Results of studies investigating the effects of context on ambiguity resolution in both non-brain-damaged and brain-damaged populations clearly suggest that both hemispheres play a role in the resolution process. Results of divided visual field studies argue for a $\mathrm{LH}$ involvement in meaning selection (Beeman, 1998; Chiarello, 1998; Faust \& Chiarello, 1998b; Faust \& Gernsbacher, 1996). This also follows from the results of some studies of nonfluent Broca's aphasic patients, where a LH lesion produced a contextual selection deficit (Hagoort, 1990; Swaab et al., 1998). The RH seems to be involved in the maintenance of meanings, as suggested by the findings of divided visual field studies (Beeman, 1998; Chiarello, 1998; Faust \& Chiarello, 1998b; Faust \& Gernsbacher, 1996). From this result, one might expect that a $\mathrm{RH}$ lesion would lead to an inability to maintain inappropriate meanings, when in fact, evidence has been provided that it may lead to sustained interference from inappropriate meanings and a failure to resolve ambiguity (Fassbinder \& Tompkins, 2001; Tompkins et al., 1997, 2000). Thus, even though RHD patients have an intact $\mathrm{LH}$, which should be able to select the contextually appropriate meaning (Faust \& Chiarello, 1998b), these individuals maintain inappropriate meanings.

One explanation for the above pattern of results is that a LH lesion does not render the selection mechanism totally unavailable, rather selection is simply delayed. If the selection mechanism were unavailable, LHD nonfluent aphasic patients would be expected to experience difficulty in resolving lexically ambiguous words because their intact RH would maintain contextually inappropriate meanings. However, under the 'delayed selection/integration' account, Broca's aphasic patients should be able to use context to select the contextually appropriate meaning at some later point in the comprehension process (Hagoort, 1990; Swaab et al., 1998). A RH lesion seems to prevent suppression of inappropriate meanings, implying that RHD patients will not be able to select the contextually appropriate meaning. However, this begs the question of why processing does not proceed through the intact $\mathrm{LH}$, which is fully able to select the appropriate meaning. This can be explained if we assume that RHD individuals have an impairment intermediate to meaning activation and selection, specifically a deficit in drawing inferences from context (or a general inability to use context). As noted above, inference deficits in RHD individuals have been demonstrated in the literature (Beeman, 1993; Beeman et al., 1994; Brownell et al., 1986). If RHD individuals cannot infer which meaning is appropriate from the context, they will be unsuccessful in resolving ambiguity.

To investigate the effects of focal $\mathrm{LH}$ or RH damage on the ability to use context in lexical ambiguity reso- lution, the present study examined LHD nonfluent aphasic and RHD individuals' sensitivity to information contained within a local (i.e., single-sentence) context. A cross-modal semantic priming task was used, in which subjects listened to sentences ending in equibiased ambiguous words and then made lexical decisions on visually presented targets, related to either the first or second meaning of the ambiguity. Sentences were constructed in such a way that each ambiguous word was embedded in three different contexts (unbiased, firstmeaning biased and second-meaning biased). Within the two-clause sentence contexts of this experiment, the second clause was always unbiased and ended in the ambiguous word, while the first clause contained the disambiguating information, except in the unbiased condition, which remained ambiguous. Control sentences were constructed by replacing sentence-final ambiguous words with unambiguous control words. To examine the time course of activation of ambiguous word meanings, all experimental trials were presented in both short $(0 \mathrm{~ms})$ and long $(750 \mathrm{~ms})$ ISI conditions.

At the short ISI, it is predicted that NBD control subjects will only show facilitation of those meanings that are contextually appropriate in biased contexts, assuming that initial activation is sensitive to local contextual constraints (i.e., following the context-sensitive view; Martin et al., 1999; Paul et al., 1992; Simpson, 1994; Tabossi et al., 1987; Vu et al., 1998, 2000). In unbiased contexts, NBD control subjects are expected to show facilitation of both meanings. In contrast, if LHD nonfluent aphasic patients are able to automatically access ambiguous word meanings, but are delayed in their ability to integrate these meanings into context (Hagoort, 1990; Swaab et al., 1998), they should show facilitation of both meanings regardless of context at the short ISI. Any predictions based on other proposals, such as the 'slowed activation' account, cannot be made with certainty, in light of the fact that this view makes predictions based on the ambiguous words having a clearly dominant meaning, which was not the case with the words used in the present study. Support for slowed activation would, however, be provided if only one meaning was facilitated, regardless of sentence bias. Finally, RHD individuals, if they have a deficit in inferring which meaning is appropriate from context, should exhibit comparable amounts of facilitation for each meaning, regardless of context at the short ISI. This prediction also follows from the 'sustained activation' hypothesis.

At the long ISI, NBD control subjects should once again only show facilitation of contextually appropriate meanings in biased contexts, and of both meanings in unbiased contexts. If LHD nonfluent aphasic patients are able to integrate appropriate meanings into context after a $750 \mathrm{~ms}$ delay, they should only show facilitation of contextually appropriate meanings in biased contexts. 
However, in unbiased contexts, they should continue to show facilitation for both meanings (similar to NBD control subjects). Results of the RHD individuals, assuming they are unable to use context to infer which meaning is appropriate (which is not expected to change with a longer prime-target interval), should closely parallel their results at the short ISI.

\section{Method}

\subsection{Subjects}

Three groups of subjects were tested: a group of LHD nonfluent aphasic individuals, a group of RHD individuals and a group of non-brain-damaged control subjects. All subjects were right-handed, native speakers of English with normal or corrected-to-normal vision. Hearing acuity was determined from a hearing screening at $<35 \mathrm{~dB} \mathrm{HL}$ at the speech frequencies $0.5,1.0$, and $2.0 \mathrm{kHz}$ and found to be within normal limits for all subjects.

Brain-damaged individuals were recruited from a number of institutions in Montreal and surrounding areas. Exclusionary criteria included multiple infarcts, history of drug or alcohol abuse and history of psychiatric or neurological illness. Lesion sites were determined based on neurological reports and radiological summaries of computerized cranial tomography (CT) or magnetic resonance imaging (MRI) scans where available. All patients were at least 6 months post-onset at the time of testing.

The LHD nonfluent aphasic group consisted of 11 individuals. Diagnosis of aphasia type was based on results of the Boston Diagnostic Aphasia Examination (BDAE) (Goodglass \& Kaplan, 1983). The RHD group consisted of nine individuals. In order to assess RHD patients' ability to generate inferences and to comprehend figurative language (skills that are frequently impaired after RH damage), these patients were administered a battery adapted from the Test of Language Competence-Expanded Edition (TLC-E) (Wiig \& Secord, 1989). In addition, all brain-damaged patients were administered further screening tests to ensure that (1) they did not exhibit potentially confounding deficits related to neglect and single word reading and (2) they had adequate auditory comprehension skills such that task instructions and materials would be understood. These screening tests included: (1) the Behavioural Inattention Test (BIT) (Wilson, Cockburn, \& Halligan, 1987) to assess visual neglect, (2) the single word-picture matching (SWPM) subtest of the Psycholinguistic Assessment of Language (PAL) (Caplan, 1992) to provide a measure of single word reading comprehension, and (3) the auditory sentence comprehension (ASC) subtest of the PAL (Caplan, 1992) to provide a measure of audi- tory sentence comprehension. Patients were excluded based on the presence of neglect (demonstrated by a score of less than $129 / 146$ on the BIT) and/or poor word and sentence comprehension (demonstrated by less than $70 \%$ accuracy on the combined score of the two subtests of the $P A L$ ). The two brain-damaged groups did not significantly differ in terms of the number of months post-onset (MPO) of stroke $[F(1,18)=1.082, p=.312]$. However, not surprisingly, they did differ in terms of their scores on the auditory sentence comprehension (ASC) subtest of the $P A L[F(1,17)=8.359, p<.01]$, with LHD nonfluent aphasic subjects having slightly lower scores overall than RHD subjects. A summary of neuroradiological, demographic and language performance data for the LHD nonfluent aphasic and RHD individuals is presented in Tables 1 and 2, respectively.

The NBD control group consisted of 20 individuals selected from a group of volunteers in the Montreal area. Control subjects were matched as closely as possible to the brain-damaged groups for age, sex and education level. Exclusionary criteria included a history of neurological and/or psychiatric illness. All control subjects were screened on a variety of neuropsychological tests to rule out the possibility of cognitive decline or dementia. These tests included the Boston Naming Test (BNT) (Kaplan, Goodglass, \& Weintraub, 1983), the MiniMental State Examination (MMSE) (Folstein, Folstein, $\&$ McHugh, 1975) and the Logical Memory I (immediate recall) and II (delayed recall) subtests of the Wechsler Memory Scale-Revised (WMS-R) (Wechsler, 1987). The number of years of education of the control subjects $(M=12.90, S D=2.51)$ was no different than that of the two brain-damaged groups $[F(2,37)=.933, p=.402]$. In addition, the age of the control subjects $(M=69.10$, $S D=6.06)$ was not significantly different from that of the brain-damaged subjects $[F(2,37)=1.018, p=.371]$.

\subsection{Materials}

Experimental stimuli consisted of 30 ambiguous words selected from Twilley, Dixon, Taylor, and Clark (1994). Only equibiased or so-called balanced ambiguous words (i.e., those having two meanings of approximately equal frequency) were chosen. ${ }^{1}$ Equibiased ambiguous words were used in an attempt to decrease the likelihood of frequency-driven meaning selection, so that the effects of context on ambiguity resolution could be for the most part isolated. Frequency of the meanings was determined from Twilley et al. (1994), who calcu-

\footnotetext{
${ }^{1}$ In most cases, even equibiased ambiguous words have one meaning which is slightly more frequent. It is important to note that in the present study, the first meaning of an equibiased ambiguous word is equated with the somewhat more frequent (i.e., dominant) meaning and the second meaning with the somewhat less frequent (i.e., subordinate) meaning.
} 
Table 1

Summary of nonfluent aphasic subjects' background information

\begin{tabular}{|c|c|c|c|c|c|c|c|c|c|c|}
\hline \multirow[t]{2}{*}{ Patient } & \multirow{2}{*}{$\begin{array}{l}\text { Age } \\
\text { (years) }\end{array}$} & \multirow{2}{*}{$\begin{array}{l}\text { Education }{ }^{\mathrm{a}} \\
\text { (years) }\end{array}$} & \multirow[t]{2}{*}{ Sex } & \multirow[t]{2}{*}{ Etiology } & \multirow[t]{2}{*}{ Lesion site ${ }^{\mathrm{b}}$} & \multirow[t]{2}{*}{ MPO } & \multirow{2}{*}{$\begin{array}{l}\text { BDAE } \\
\text { AC }^{\mathrm{c}} \\
(\text { Mean \%ile) }\end{array}$} & \multirow{2}{*}{$\begin{array}{l}\text { BNT } \\
(60)\end{array}$} & \multicolumn{2}{|l|}{ PAL } \\
\hline & & & & & & & & & $\begin{array}{l}\text { SWPM } \\
(32)\end{array}$ & $\begin{array}{l}\text { ASC } \\
(40)\end{array}$ \\
\hline 1 & 72 & 12 & $\mathrm{~F}$ & I & L parietal & 80 & 89 & 53 & 32 & 40 \\
\hline 2 & 80 & 9 & M & $\mathrm{H}$ & $\mathrm{L}$ frontal & 57 & 89 & 55 & 30 & 34 \\
\hline 3 & 76 & 12 & M & I & L MCA distribution & 51 & 84 & $\mathrm{n} / \mathrm{a}$ & 27 & 28 \\
\hline 4 & 52 & 14 & M & I & L parietal & 148 & 90 & 45 & 32 & 32 \\
\hline 5 & 68 & 9 & $\mathrm{~F}$ & $\mathrm{H}$ & L frontal-temporal-parietal & 80 & 60 & 15 & 32 & 27 \\
\hline 6 & 83 & 8 & $\mathrm{~F}$ & $\mathrm{n} / \mathrm{a}$ & $\mathrm{n} / \mathrm{a}$ & 77 & 83 & 39 & 31 & 31 \\
\hline 7 & 48 & 15 & $\mathrm{~F}$ & I & L frontal-parietal & 102 & 88 & 43 & 31 & 36 \\
\hline 8 & 74 & 16 & $\mathrm{M}$ & I & L MCA distribution & 35 & 15 & 18 & 32 & 37 \\
\hline 9 & 73 & 12 & $\mathrm{M}$ & I & L temporal-parietal & 120 & 93 & $\mathrm{n} / \mathrm{a}$ & 31 & 35 \\
\hline 10 & 82 & 12 & $\mathrm{~F}$ & I & L MCA distribution & 16 & 84 & 24 & 30 & 35 \\
\hline 11 & 68 & 11 & $\mathrm{~F}$ & I & L frontal-parietal & 60 & 83 & 18 & 32 & 30 \\
\hline$M$ & 70.55 & 11.82 & & & & 75.09 & 78.00 & 34.44 & 30.91 & 33.18 \\
\hline$S D$ & 11.36 & 2.52 & & & & 37.87 & 22.64 & 15.81 & 1.51 & 3.97 \\
\hline
\end{tabular}

Note. H, hemorrhage; I, ischemic infarct; MCA, middle cerebral artery; MPO, months post-onset; n/a, information not available.

${ }^{a}$ Best estimated conversion into years, based on information from subject (e.g., 2 years college, high school).

${ }^{\mathrm{b}}$ Established based on CT/MRI scan and/or neurological reports.

${ }^{\mathrm{c}}$ Mean of percentiles on four auditory comprehension subtests of the BDAE.

Table 2

Summary of right-hemisphere-damaged subjects' background information

\begin{tabular}{|c|c|c|c|c|c|c|c|c|c|}
\hline \multirow[t]{2}{*}{ Patient } & \multirow{2}{*}{$\begin{array}{l}\text { Age } \\
\text { (years) }\end{array}$} & \multirow{2}{*}{$\begin{array}{l}\text { Education }^{\mathrm{a}} \\
\text { (years) }\end{array}$} & \multirow[t]{2}{*}{ Sex } & \multirow[t]{2}{*}{ Etiology } & \multirow[t]{2}{*}{ Lesion site ${ }^{\mathrm{b}}$} & \multirow[t]{2}{*}{ MPO } & \multicolumn{2}{|c|}{ TLC-E (adapted) } & \multirow{2}{*}{$\begin{array}{l}\text { PAL } \\
\text { ASC } \\
(40)\end{array}$} \\
\hline & & & & & & & $\begin{array}{l}\text { Figurative } \\
\text { (10) }\end{array}$ & $\begin{array}{l}\text { Inferences } \\
\text { (10) }\end{array}$ & \\
\hline 1 & 60 & 13 & $\mathrm{~F}$ & $\mathrm{H}$ & R PCA distribution & 129 & 8 & 10 & 40 \\
\hline 2 & 66 & 13 & $\mathrm{~F}$ & $\mathrm{H}$ & $\mathrm{R}$ basal ganglia (subcortical) & 69 & $\mathrm{n} / \mathrm{a}$ & $\mathrm{n} / \mathrm{a}$ & $\mathrm{n} / \mathrm{a}$ \\
\hline 3 & 43 & 9 & $\mathrm{~F}$ & I & $\mathrm{R}$ MCA distribution & 52 & 6 & 4 & 36 \\
\hline 4 & 88 & 11 & M & $\mathrm{H}$ & $\mathrm{n} / \mathrm{a}$ & 48 & 7 & 6 & 38 \\
\hline 5 & 34 & 13 & $\mathrm{~F}$ & I & $\mathrm{R}$ MCA distribution & 67 & 9 & 10 & 38 \\
\hline 6 & 71 & 14 & M & $\mathrm{H}$ & $\mathrm{R}$ thalamus (subcortical) & 52 & 6 & 7 & 37 \\
\hline 7 & 72 & 12 & M & $\mathrm{n} / \mathrm{a}$ & $\mathrm{R}$ parietal & 58 & 9 & 8 & 39 \\
\hline 8 & 79 & 11 & M & I & $\mathrm{R}$ temporal-parietal & 45 & 7 & 7 & 37 \\
\hline 9 & 63 & 12 & $\mathrm{M}$ & $\mathrm{n} / \mathrm{a}$ & $\mathrm{n} / \mathrm{a}$ & 7 & 7 & 6 & 35 \\
\hline$M$ & 64.00 & 12.00 & & & & 58.56 & 7.38 & 7.25 & 37.50 \\
\hline$S D$ & 16.87 & 1.50 & & & & 31.98 & 1.19 & 2.05 & 1.60 \\
\hline
\end{tabular}

Note. H, hemorrhage; I, Ischemic infarct; MCA, middle cerebral artery; MPO, months post-onset; n/a, information not available; PCA, posterior cerebral artery.

${ }^{\text {a }}$ Best estimated conversion into years, based on information from subject (e.g., 2 years college, high school).

${ }^{\mathrm{b}}$ Established based on CT/MRI scan and/or neurological reports.

lated a balance estimate to determine the overall ambiguity of each word. This estimate is based on a calculation involving only the two most frequent meanings of the ambiguous word and the proportion of responses given for each meaning. To provide a better indication of the relationship between the two meanings of the ambiguous words used in this study, the frequency of occurrence of the first meaning was never greater than .70 and the frequency of occurrence of the second meaning was at least .20 (in order to exclude very infrequent meanings). Overall, the first meaning had a mean frequency of .52 (range: .36-.70) and the second meaning had a mean frequency of .33 (range: .20-.48).
These values are comparable to those of balanced ambiguous words used in previous studies (Binder \& Morris, 1995; Duffy et al., 1988; Rayner \& Duffy, 1986; Rayner \& Frazier, 1989; Sereno, 1995).

For each ambiguous word, three sentence contexts were constructed: an unbiased (i.e., ambiguous) context, one biased toward the first meaning and another biased toward the second meaning. All sentences were composed of two clauses (7-10 words in total), with the second (unbiased) clause held constant across the three contexts. The first clause was manipulated in each condition to create the appropriate context (see example stimuli provided in Table 3). Sentence length was held 
Table 3

Example of experimental stimuli

\begin{tabular}{llll}
\hline Context & Sentence prime & Visual targets \\
\cline { 3 - 4 } & & First meaning & Second meaning \\
\hline Unbiased & Before giving it to her, he looked at the CARD (TEST) & birthday & poker \\
First-meaning biased & After writing a long message, he looked at the CARD (TEST) & birthday & poker \\
Second-meaning biased & Although trying not to cheat, he looked at the CARD (TEST) & birthday & poker \\
\hline
\end{tabular}

Note. Control words given in parentheses replaced sentence-final ambiguous words in control sentences.

constant across the three context types and the ambiguous word was always embedded in the second unbiased clause. Thus, results can only be attributed to the effects of the first clause. In constructing each of the sentences, the use of figurative language was also avoided, so as not to introduce a potential confound for RHD individuals. Control sentences were constructed by replacing sentence-final ambiguous words with unambiguous control words while keeping all other elements of the sentences identical (see Table 3). Control words were selected to form possible completions to the sentences in each context. They were also matched to the ambiguous words for frequency (Francis \& Kucera, 1982) and length. Sentences were recorded by a female speaker of English, digitized at a rate of $20 \mathrm{~K}$ samples/second and low pass filtered at $9 \mathrm{kHz}$ using the Brown Lab Interactive Speech System (BLISS) software (Mertus, 2000).

To establish that biased sentences ending in ambiguous words were indeed biased toward their intended meaning and that unbiased sentences and sentences ending in control words were not biased, a bias norming test was conducted. Experimental sentences and their controls were assigned to three different versions of the test, with the restriction that sentences ending in the same ambiguous or control word not appear in the same version. In this way, none of the subjects saw a sentencefinal word more than once. Each version of the test was given to 11 neurologically intact subjects (age range: 19 $60, M=33.84, S D=10.27$ ). To complete the test, subjects were asked to read each of the sentences carefully and to then write down the first word which came to their mind after reading the final (i.e., ambiguous) word of each sentence. Subjects were not informed about the ambiguous nature of the sentence-final words. Responses were independently coded as to whether they were related to the first or second meaning (after missing responses and those unrelated to either meaning were discarded). Appropriateness of the bias was established if the majority of subjects' responses were in agreement with the particular bias intended. For first-meaning biased sentences, $83 \%$ of subjects' responses were related to the intended meaning, while for second-meaning biased sentences, $79 \%$ of subjects' responses were related to the intended meaning. For unbiased sentences, it was not always the case that an equal number of subjects' responses were related to each meaning, however the proportion of subjects' responses to each meaning was more comparable; $62 \%$ of responses were related to the first meaning and $38 \%$ to the second meaning.

Visual targets were associates related to each of the meanings of the ambiguous words, selected from the Twilley et al. (1994) norms and in some cases from responses given in the above-mentioned bias norming test. These targets were paired with experimental (i.e., ambiguity- or control-bearing) sentences in each of the three contexts (see Table 3). To avoid the development of strategies by subjects, an equal number of filler sentences was constructed, half of which ended in an ambiguous word and the other half in an unambiguous word. These sentences were similar in length and style to the critical sentences. Following the presentation of filler sentences, a pronounceable nonword was presented for lexical decision. Nonwords were approximately matched to word targets for length and were orthographically legal letter strings.

Twelve lists (six per ISI) were created such that neither auditory sentence primes nor visual targets were repeated within a list. Each list contained 30 ambiguitybearing sentences with word targets, 30 control-bearing sentences with word targets and 60 filler sentences with nonword targets (120 sentence trials in total). Trials within each list were presented in a random order, with randomization controlled by the computer.

\subsection{Procedure}

All patients were tested in six sessions of approximately $45 \mathrm{~min}$ each (three sessions per ISI). Control subjects were randomly assigned to only one ISI condition; thus they completed three sessions in total. Within each session, subjects were presented with two lists, in a blocked design. Order of presentation of the lists was counterbalanced across all subjects and ISI was counterbalanced across the patients. Within each ISI condition, the three sessions were separated by at least 1 week (to minimize effects of repetition). For the patient groups, at least 8 weeks elapsed before testing of the second ISI condition commenced.

Subjects were tested individually, seated in a comfortable position and at an appropriate viewing distance from the computer screen. Each trial began with the presentation of an auditory sentence through head- 
phones. At 0 or $750 \mathrm{~ms}$ after the offset of the sentencefinal ambiguous or control word, a visual target was centrally displayed on the computer screen. Subjects were instructed to make a lexical decision response to the visual target by pressing the YES key for a word and the NO key for a nonword on a response box located in front of them (using their currently dominant hand). The computer recorded both reaction time (in $\mathrm{ms}$ ) and accuracy. Reaction time was recorded from the onset of the visual target until the subject responded. After $4900 \mathrm{~ms}$ without a response, the trial was recorded as a no-response. The inter-trial interval was $5000 \mathrm{~ms}$. A practice session of 10 trials preceded presentation of the experimental stimuli. In cases where subjects did not understand the task, the practice session was repeated. To ensure that subjects listened to the sentences, they were administered a recognition task (containing some of the previously presented filler sentences). Subjects were informed about the recognition task at the beginning of the session and were required to check off which sentences they remembered hearing from a list of sentences at the end of the session.

\section{Results}

Accuracy rates for lexical decision responses were first examined to identify and exclude data from stimulus lists with unusually high error rates. It should also be noted that no speed/accuracy trade-offs were apparent in any of the groups. For each subject, accuracy rates were calculated for each of the six experimental lists in each ISI condition. Examining accuracy rates within a particular list seemed justified, as subjects may have had a high accuracy rate overall, but not necessarily within all lists. Moreover, as each list was administered separately, error rates could have potentially varied among the lists (especially within the patient groups). A cutoff rate of $67 \%$ was used, resulting in any list where a subject made more than 33\% errors being removed. For two nonfluent aphasic subjects (S3 and S8), two lists were removed because of high error rates. This resulted in their reaction time results being based on four of six lists in the particular ISI condition $(0 \mathrm{~ms}$ ISI for S8 and $750 \mathrm{~ms}$ ISI for S3). In addition, one list was not completed by an RHD subject (S4) due to computer error. In terms of the distribution of errors, all subject groups made less than $3.1 \%$ real word errors on critical trials, showing that they were able to perform the task with a high degree of accuracy. NBD control subjects made a total of $0.47 \%$ real word errors $(34 / 7200$ trials). LHD nonfluent aphasic individuals made a total of $3.09 \%$ real word errors (237/7680 trials), while RHD individuals made a total of $1.93 \%$ real word errors (124/ 6420 trials). The distribution of errors (related versus control) did not statistically differ among the subject groups $[F(2,37)=.318, p=.730]$. Moreover, given that accuracy did not vary as a function of any of the experimental conditions in this study, the discussion will be restricted to results of the reaction time (RT) data.

Statistical analyses were carried out on the RTs for correct (i.e., YES) responses to real word targets. These analyses were conducted only after extreme values (i.e., RTs less than $300 \mathrm{~ms}$ and greater than $4000 \mathrm{~ms}$ ) and outliers (RTs greater or less than 3 standard deviations from each subjects' mean per condition) were removed. The total number of outliers removed was $1.56 \%$ for NBD control subjects, $1.56 \%$ for LHD nonfluent aphasic subjects and $1.70 \%$ for RHD individuals. The resulting mean RTs for each group per condition and ISI are reported in Tables 4-6. As the data violated the assumption of multivariate normality, RTs were normalized using a $\log$ transformation (Stevens, 1996). A $3 \times 2 \times 2$ (Sentence Context $\times$ Prime Relatedness $\times$ Target Type) repeated measures analysis of variance (ANOVA) with subjects $(F 1)$ and items $(F 2)$ as random factors was then conducted on each group's RT data, separately for each ISI condition. In addition, planned pairwise comparisons of related and control RTs in all conditions were conducted on each group's data in order to determine whether or not facilitation was observed for targets related to the first or second meanings of the ambiguous words in each context (see rationale provided in Hagoort, 1990 and Swinney et al., 1989).

\subsection{0-ms ISI condition}

For NBD control subjects, there were significant main effects of Target Type $[F 1(1,9)=19.069, p<.01$; $F 2(1,29)=4.269, \quad p<.05]$ and Prime Relatedness $[F 1(1,9)=4.650, p=.059 ; F 2(1,29)=7.336, p<.01]$. In addition, there was a significant interaction of Sentence Context $\times$ Prime Relatedness $\times$ Target Type though only in the item analysis $[F 1(2,8)=2.725$, $p=.125 ; F 2(2,28)=6.452, p<.01]$. Planned comparisons between related and control conditions revealed that only targets related to the first meaning of the ambiguous word were facilitated in first-meaning biased contexts $[F 1(1,9)=5.415, p<.05 ; F 2(1,29)=8.634$, $p<.01]$, while targets related to the second meaning were not $[F 1(1,9)=.241, p=.635 ; F 2(1,29)=.266$, $p=.610]$. Inspection of the individual data revealed that this pattern of facilitation was evidenced by $70 \%$ of the control subjects. In second-meaning biased contexts, only targets related to the second meaning were facilitated $[F 1(1,9)=6.741, \quad p<.05 ; \quad F 2(1,29)=17.220$, $p<.0001]$, and not targets related to the first meaning $[F 1(1,9)=1.247, p=.293 ; F 2(1,29)=1.179, p=.287]$. This pattern of performance was again exhibited by $70 \%$ of the control subjects. Somewhat surprisingly, in unbiased contexts, where targets related to both the first and second meanings were expected to show facilitation, 
Table 4

Mean reaction times and standard deviations (in $\mathrm{ms}$ ), and percentage of errors for control subjects as a function of Sentence Context, Prime Relatedness, Target Type and ISI

\begin{tabular}{|c|c|c|c|c|c|c|}
\hline \multirow[t]{2}{*}{ Target type } & \multicolumn{2}{|c|}{ Unbiased } & \multicolumn{2}{|c|}{ First meaning biased } & \multicolumn{2}{|c|}{ Second meaning biased } \\
\hline & Related & Control & Related & Control & Related & Control \\
\hline \multicolumn{7}{|c|}{ Oms ISI } \\
\hline \multicolumn{7}{|c|}{ First meaning } \\
\hline$M$ & 994 & 1011 & 972 & 1032 & 997 & 1014 \\
\hline$S D$ & 122 & 145 & 130 & 140 & 118 & 117 \\
\hline$\%$ Error & 1.3 & 1.3 & 1.3 & 1.0 & 0.7 & 1.3 \\
\hline \multicolumn{7}{|c|}{ Second meaning } \\
\hline$M$ & 974 & 978 & 999 & 989 & 944 & 993 \\
\hline$S D$ & 130 & 117 & 149 & 129 & 115 & 126 \\
\hline$\%$ Error & 0.3 & 0.3 & 0.0 & 0.3 & 0.0 & 0.0 \\
\hline \multicolumn{7}{|c|}{$750 \mathrm{~ms} I S I$} \\
\hline \multicolumn{7}{|c|}{ First meaning } \\
\hline$M$ & 995 & 1011 & 989 & 1010 & 1006 & 1024 \\
\hline$S D$ & 204 & 190 & 189 & 186 & 193 & 197 \\
\hline$\%$ Error & 0.7 & 0.0 & 0.7 & 0.3 & 0.0 & 0.0 \\
\hline \multicolumn{7}{|c|}{ Second meaning } \\
\hline$M$ & 1002 & 1005 & 1003 & 1001 & 973 & 1003 \\
\hline$S D$ & 197 & 193 & 183 & 193 & 191 & 182 \\
\hline$\%$ Error & 0.7 & 0.3 & 0.0 & 0.0 & 0.3 & 0.3 \\
\hline
\end{tabular}

Note. ISI, interstimulus interval.

Table 5

Mean reaction times and standard deviations (in ms), and percentage of errors for nonfluent aphasic subjects as a function of Sentence Context, Prime Relatedness, Target Type and ISI

\begin{tabular}{|c|c|c|c|c|c|c|}
\hline \multirow[t]{2}{*}{ Target type } & \multicolumn{2}{|c|}{ Unbiased } & \multicolumn{2}{|c|}{ First meaning biased } & \multicolumn{2}{|c|}{ Second meaning biased } \\
\hline & Related & Control & Related & Control & Related & Control \\
\hline \multicolumn{7}{|c|}{$0 \mathrm{~ms} I S I$} \\
\hline \multicolumn{7}{|c|}{ First meaning } \\
\hline$M$ & 1171 & 1212 & 1184 & 1231 & 1203 & 1193 \\
\hline$S D$ & 252 & 275 & 288 & 326 & 315 & 279 \\
\hline$\%$ Error & 3.4 & 3.4 & 1.9 & 3.1 & 2.8 & 4.4 \\
\hline \multicolumn{7}{|c|}{ Second meaning } \\
\hline$M$ & 1157 & 1198 & 1167 & 1201 & 1176 & 1181 \\
\hline$S D$ & 272 & 328 & 287 & 306 & 289 & 295 \\
\hline$\%$ Error & 3.1 & 2.5 & 2.8 & 1.6 & 3.1 & 1.6 \\
\hline \multicolumn{7}{|c|}{$750 \mathrm{~ms} I S I$} \\
\hline \multicolumn{7}{|c|}{ First meaning } \\
\hline$M$ & 1202 & 1185 & 1200 & 1219 & 1216 & 1219 \\
\hline$S D$ & 218 & 206 & 251 & 216 & 194 & 230 \\
\hline$\%$ Error & 3.8 & 3.8 & 3.4 & 4.1 & 3.8 & 4.7 \\
\hline \multicolumn{7}{|c|}{ Second meaning } \\
\hline$M$ & 1202 & 1205 & 1229 & 1203 & 1213 & 1193 \\
\hline$S D$ & 221 & 212 & 195 & 198 & 218 & 195 \\
\hline$\%$ Error & 1.6 & 3.4 & 2.8 & 3.4 & 2.8 & 2.8 \\
\hline
\end{tabular}

Note. ISI, interstimulus interval.

no significant effects were obtained (all $F$ s $<1$ ). Inspection of the individual data revealed no consistent pattern of facilitation in this context, although $50 \%$ of subjects did prime one or the other meaning (but never both meanings).
Analysis of the results for the LHD nonfluent aphasic subjects yielded significant main effects of Prime Relatedness $[F 1(1,10)=11.016, p<.01 ; F 2(1,29)=8.239$, $p<.01]$ and Target Type (by subjects only) $[F 1(1,10)=$ $10.754, p<.01 ; F 2(1,29)=1.784, p=.192]$. Planned 
Table 6

Mean reaction times and standard deviations (in ms), and percentage of errors for right hemisphere-damaged subjects as a function of Sentence Context, Prime Relatedness, Target Type and ISI

\begin{tabular}{|c|c|c|c|c|c|c|}
\hline \multirow[t]{2}{*}{ Target type } & \multicolumn{2}{|c|}{ Unbiased } & \multicolumn{2}{|c|}{ First meaning biased } & \multicolumn{2}{|c|}{ Second meaning biased } \\
\hline & Related & Control & Related & Control & Related & Control \\
\hline \multicolumn{7}{|c|}{ Oms ISI } \\
\hline \multicolumn{7}{|c|}{ First meaning } \\
\hline$M$ & 1016 & 1046 & 993 & 1019 & 1013 & 1040 \\
\hline$S D$ & 210 & 211 & 206 & 228 & 201 & 210 \\
\hline$\%$ Error & 1.1 & 1.5 & 0.4 & 1.5 & 0.8 & 0.4 \\
\hline \multicolumn{7}{|c|}{ Second meaning } \\
\hline$M$ & 1036 & 1038 & 1032 & 1020 & 1021 & 1014 \\
\hline$S D$ & 213 & 211 & 201 & 230 & 223 & 215 \\
\hline$\%$ Error & 1.5 & 1.9 & 1.1 & 1.1 & 1.5 & 1.5 \\
\hline \multicolumn{7}{|c|}{$750 \mathrm{~ms} I S I$} \\
\hline \multicolumn{7}{|c|}{ First meaning } \\
\hline$M$ & 1038 & 1071 & 1042 & 1050 & 1075 & 1084 \\
\hline$S D$ & 183 & 196 & 187 & 205 & 186 & 187 \\
\hline$\%$ Error & 2.6 & 3.7 & 3.0 & 3.0 & 3.7 & 3.0 \\
\hline \multicolumn{7}{|c|}{ Second meaning } \\
\hline$M$ & 1026 & 1028 & 1081 & 1059 & 1021 & 1049 \\
\hline$S D$ & 181 & 194 & 199 & 184 & 173 & 190 \\
\hline$\%$ Error & 1.9 & 1.5 & 2.2 & 2.6 & 1.9 & 3.0 \\
\hline
\end{tabular}

Note. ISI, interstimulus interval.

comparisons revealed that in first-meaning biased contexts, targets related to the first meaning $[F 1(1,10)=$ $4.800, p=.053 ; F 2(1,29)=2.289, p=.141]$ were facilitated (though only marginally significant in the subject analysis) as well as targets related to the second meaning $[F 1(1,10)=4.249, p=.066 ; F 2(1,29)=3.463, p=.073]$ (though only marginally significant in both analyses). Though this result reflects the group performance, it should be noted that $45 \%$ of subjects showed a similar pattern of results as the control subjects, namely activation of the contextually appropriate first meaning only. In unbiased contexts, there was also a trend (in the item analysis) toward facilitation of targets related to both the first $[F 1(1,10)=2.498, p=.145 ; F 2(1,29)=$ $3.115, p=.088]$ and second meanings $[F 1(1,10)=2.964$, $p=.116 ; F 2(1,29)=3.806, p=.061]$, though upon inspection of the individual data, this pattern of performance was only demonstrated by $36 \%$ of the subjects. ${ }^{2}$ In second-meaning biased contexts, no facilitation was observed (all $F \mathrm{~s}<1$ ), even though some individuals in the group did exhibit priming. Crucially, only $36 \%$ of the subjects showed the context-selective performance of the control subjects in this context.

For RHD individuals, there was a significant main effect of Sentence Context in the subject analysis

\footnotetext{
${ }^{2}$ Though neither of these effects was significant, they are indicative of a trend toward first- and second-meaning related targets being facilitated in unbiased contexts. The lack of significance here is likely due to the large amount of variance within the LHD nonfluent aphasic groups' RT data.
}

$[F 1(2,7)=5.109, p<.05 ; F 2(2,28)=2.020, p=.152]$ and a marginally significant interaction of Prime Relatedness $\times$ Target Type in both analyses $[F 1(1,8)=$ $3.930, p=.083 ; F 2(1,29)=3.525, p=.071]$. Planned comparisons revealed that facilitation was observed in unbiased contexts, but only for targets related to the first meaning of the ambiguous word (by subjects only) $[F 1(1,8)=5.913, p<.05 ; F 2(1,29)=2.872, p=.101]$, and not for targets related to the second meaning $[F 1(1,8)=.051, p=.827 ; F 2(1,29)=.013, p=.911]$. Inspection of the individual data revealed that this pattern of performance was not consistent, as only $44 \%$ of the subjects fell in line with the group result. In secondmeaning biased contexts, there was also a trend (in the subject analysis) toward targets related to the first meaning being facilitated $[F 1(1,8)=3.788, p=.087$; $F 2(1,29)=1.147, p=.293$ ], but not targets related to the second meaning $[F 1(1,8)=.156, p=.704 ; F 2$ $(1,29)=.006, p=.941]$. No significant facilitation was observed in first-meaning biased contexts. Individual patterns of performance in biased contexts showed that only $33 \%$ of the subjects exhibited context-selective activation in first-meaning biased contexts and only $11 \%$ in second-meaning biased contexts.

In sum, NBD control subjects appeared to be influenced by context at the short ISI, in that they only showed facilitation for contextually appropriate meanings of the ambiguous word in both first- and secondmeaning biased contexts. Surprisingly, in unbiased contexts, where both meanings were expected to show facilitation, these subjects did not demonstrate 
facilitation for either meaning. In contrast, neither patient group was influenced by context at the short ISI in a parallel manner. LHD nonfluent aphasic subjects showed facilitation for both meanings of the ambiguous word in first-meaning biased contexts (and a trend toward this same pattern in unbiased contexts) and no facilitation in second-meaning biased contexts. RHD subjects showed facilitation of only the first meaning of the ambiguous word in unbiased contexts and a trend toward facilitation of only the first meaning in secondmeaning biased contexts. In first-meaning biased contexts, neither meaning was facilitated for these subjects.

\subsection{0-ms ISI condition}

For NBD control subjects at the $750 \mathrm{~ms}$ ISI, there were significant main effects of Prime Relatedness $[F 1(1,9)=11.231, p<.01 ; F 2(1,29)=7.157, p<.05]$ and Target Type (by subjects only) $[F 1(1,9)=5.287$, $p<.05 ; F 2(1,29)=.606, p=.443]$. There was also a significant interaction of Sentence Context $\times$ Target Type $[F 1(2,8)=4.860, \quad p<.05 ; \quad F 2(2,28)=5.008$, $p<.05]$. Planned comparisons revealed that similar to the 0 -ms ISI condition, only targets related to the first meaning of the ambiguous word were facilitated in firstmeaning biased contexts (by subjects only) $[F 1(1,9)=$ $8.659, p<.05 ; F 2(1,29)=2.489, p=.126]$, and not targets related to the second meaning $[F 1(1,9)=.085$, $p=.777 ; F 2(1,29)=.107, p=.746]$. This pattern of performance was somewhat variable, as only $60 \%$ of the control subjects exhibited the group performance. In second-meaning biased contexts, only targets related to the contextually appropriate second meaning were facilitated $[F 1(1,9)=6.885, p<.05 ; F 2(1,29)=6.288$, $p<.05$ ], whereas targets related to the first meaning were not $[F 1(1,9)=3.089, \quad p=.113 ; \quad F 2(1,29)=2.148$, $p=.153]$. This pattern of performance was demonstrated by $70 \%$ of the subjects. In unbiased contexts, targets related to the first meaning produced a marginally significant amount of facilitation in the subject analysis $[F 1(1,9)=4.549, p=.062 ; F 2(1,29)=2.504$, $p=.124]$, whereas targets related to the second meaning showed no facilitation $[F 1(1,9)=.131, p=.726$; $F 2(1,29)=.251, p=.620]$. Individual performance in this condition was much less consistent, as only $50 \%$ of the subjects showed the group trend.

For LHD nonfluent aphasic patients, no main effects or interactions were found to be significant at the $750 \mathrm{~ms}$ ISI. In addition, targets related to the first and second meanings of the ambiguous words failed to be significantly facilitated in any of the contexts, as indicated by the results of planned comparisons. As in the 0-ms ISI condition, a great deal of variability was observed upon inspection of the individual data. In first-meaning biased contexts, only $36 \%$ of the subjects demonstrated a similar pattern of facilitation as the control subjects. Simi- larly, in second-meaning biased contexts, only $27 \%$ of the subjects fell in line with the results of the control subjects. In unbiased contexts, no predictable pattern could be discerned. Moreover, only $27 \%$ of the subjects demonstrated facilitation of targets related to the first meaning (in line with the trend shown by the control subjects).

For RHD individuals, there was a significant interaction of Sentence Context $\times$ Target Type $[F 1(2,7)=$ $6.283, p<.05 ; F 2(2,28)=6.570, p<.01]$ at the $750 \mathrm{~ms}$ ISI. Planned comparisons revealed that facilitation occurred only for targets related to the first meaning of the ambiguous word in unbiased contexts $[F 1(1,8)=7.200$, $p<.05 ; F 2(1,29)=5.195, p<.05]$. In this same context, targets related to the second meaning were not facilitated $[F 1(1,8)=.003, p=.954 ; F 2(1,29)=.176, p=.678]$. In terms of the individual data, $44 \%$ of the subjects produced this pattern of results. In second-meaning biased contexts, there was also a trend in the item analysis toward targets related to the contextually appropriate second meaning being facilitated $[F 1(1,8)=2.864$, $p=.129 ; F 2(1,29)=3.596, p=.068]$, but not targets related to the first meaning $[F 1(1,8)=.083, p=.780$; $F 2(1,29)=.153, p=.699]$. Performance in this condition was extremely variable, as only $33 \%$ of the subjects evidenced the group trend. In first-meaning biased contexts, no significant facilitation was observed for targets related to either meaning. Inspection of the individual data in this context showed that only 33\% of RHD subjects demonstrated the context-selective pattern of facilitation of the control subjects.

In sum, results for NBD control subjects at the long ISI closely paralleled their results at the short ISI, namely context-sensitive facilitation of ambiguous word meanings in first- and second-meaning biased contexts. Again, no significant facilitation was observed in unbiased contexts, however a trend toward facilitation of the first meaning was present. In contrast, LHD nonfluent aphasic patients demonstrated reduced levels of activation at the long ISI across all contexts, with no facilitation observed for either meaning of the ambiguous words. Finally, RHD subjects once again only showed facilitation for the first meaning of the ambiguous word in an unbiased (i.e., ambiguous) context. In secondmeaning biased contexts, they did however appear to be more influenced by context, as a trend toward the contextually appropriate meaning being facilitated was observed. As in the short ISI condition, no facilitation was observed in first-meaning biased contexts.

\section{Discussion}

The present study used a cross-modal semantic priming paradigm to investigate the effect of $\mathrm{LH}$ and RH damage on the ability to use local (i.e., single-sen- 
tence) contextual information to resolve lexically ambiguous words. Results indicate that different patterns of activation of ambiguous word meanings emerge for NBD control, LHD nonfluent aphasic and RHD subjects. At both the short and long ISIs, the brain-damaged groups did not appear to be greatly influenced by the preceding context, in sharp contrast to the control subjects, who were able to use the context to select which meaning was appropriate. As LHD nonfluent aphasic subjects showed some evidence of activation of both meanings of ambiguous words at the short ISI and no evidence of any activation at the long ISI, their deficit does not appear to stem from an inability to automatically access word meanings, but more from an inability to use context (Hagoort, 1990; Swaab et al., 1998), combined with a faster than normal decay rate of lexical activation (Haarmann \& Kolk, 1994; Kolk, 1995; Kolk \& Van Grunsven, 1985). As RHD subjects activated only first meanings in two of the three contexts at the short ISI and first meanings in unbiased contexts and contextually appropriate meanings in second-meaning biased contexts at the long ISI, their deficit also seems to result from an inability to initially use context (Cook, 1989; Cook \& Beech, 1990), combined with an over-reliance on frequency in the activation of ambiguous word meanings.

\subsection{Sensitivity to context and lexical ambiguity resolution in NBD control subjects}

In biased contexts, NBD control subjects were expected to activate only contextually appropriate meanings at both short and long ISIs. Consistent with this prediction, individuals in the present study demonstrated selective activation of contextually appropriate meanings in both first- and second-meaning biased contexts at both ISIs. As such, the control subject data provide further support for the context-sensitive (or context-dependent) view of ambiguity resolution (e.g., Martin et al., 1999; Simpson, 1994; Vu et al., 1998, 2000). These individuals were able to use context very early on in the processing of ambiguous words and continued to be influenced by context at a later point in the comprehension process. In unbiased contexts, it was predicted that control subjects would activate both meanings, as the ambiguous words in the present study had two meanings of approximately equal frequency. Contrary to this prediction, the control subjects did not activate either meaning at the short ISI and only produced a trend toward activation of the first meaning at the long ISI. In prior studies using unbiased (i.e., ambiguous) sentences, young control subjects have been shown to activate only the dominant (i.e., most frequent) meaning of unequibiased ambiguous words (Simpson, 1981; Simpson \& Krueger, 1991; Titone, 1998). Though under some conditions, they have been shown to activate both meanings (using a $300 \mathrm{~ms}$ ISI; Simpson \& Krueger, 1991). The conclusion to be drawn from these studies is that in the absence of a disambiguating context, frequency determines which meaning will be activated, though only in cases where the ambiguous words have a clearly dominant meaning. When the ambiguous words have two meanings of relatively equal frequency, as did the words used in the present study, it is not the case that one meaning can be selected on the basis of frequency. Because neither context nor frequency could be used to select which interpretation was the most likely in unbiased contexts in the present study, perhaps neither meaning was able to reach a sufficient threshold of activation.

\subsection{Context insensitivity and rapid decay of lexical activation in LHD nonfluent aphasic individuals}

At the short ISI, LHD nonfluent aphasic individuals were expected to activate both meanings regardless of context, assuming they were delayed in their ability to integrate these meanings into context. In contrast, at the long ISI, they were expected to activate only contextually appropriate meanings in biased contexts, as a $750 \mathrm{~ms}$ delay should have allowed enough time for appropriate meanings to be integrated into the context. In addition, they were expected to activate both meanings in unbiased contexts at the long ISI. Consistent with the initial prediction, when activation was probed at a short ISI (0 ms), LHD nonfluent aphasic individuals showed a trend toward activation of both meanings of the ambiguous words in first-meaning biased and unbiased contexts. From this result, it can be inferred that while they were able to activate more than one meaning (cf. Prather et al., 1994; Swinney et al., 1989), they were unable to use the context to complete the process of ambiguity resolution (Hagoort, 1990; Swaab et al., 1998). By comparison, when activation was probed at a longer ISI $(750 \mathrm{~ms})$, the nonfluent aphasic subjects were unable to activate either meaning in any of the three contexts, in contrast with initial predictions. Thus, activation of ambiguous word meanings appeared to decay at a faster than normal rate (see Haarmann \& Kolk, 1994; Kolk, 1995; Kolk \& Van Grunsven, 1985 for a similar proposal with respect to the rapid decay of syntactic information). In light of these findings, it is important to consider not only how the time course of lexical activation may be altered in nonfluent aphasia, but also how sensitivity to biasing information from different types of contexts may be affected. Each of these issues will be dealt with in turn.

That nonfluent aphasic individuals have difficulty in using context to resolve lexically ambiguous words is supported by the results at the short ISI, in line with previous studies (Hagoort, 1990; Swaab et al., 1998). That their deficit affects sensitivity to some contexts 
more than others is a new issue raised by the present findings. Nonfluent aphasic individuals in this study appeared to be less sensitive to contexts biased toward the second meaning of ambiguous words than to other types of contexts. Only in these contexts did they consistently fail to activate either meaning, posing a challenge to the results of previous studies, in which nonfluent Broca's aphasic patients were able to activate ambiguous word meanings in dominant- and subordinate-meaning biased contexts (Hagoort, 1990; Swaab et al., 1998; Swinney et al., 1989). Though this lack of sensitivity to second-meaning biased contexts may have occurred at both ISIs, a strong case can only be made for it at the short ISI, since no activation was observed in any context at the long ISI. In the only prior study to look at sensitivity of the cerebral hemispheres to sentence contexts emphasizing different aspects of subordinate (i.e., less frequent) word meanings, Titone (1998) found that the LH was only sensitive to contexts biasing central semantic features (i.e., strong contexts) and not to contexts biasing peripheral semantic features (i.e., weak contexts). This finding suggests that damage to the LH could result in a selective impairment in activating ambiguous word meanings in a subordinate-biased context, if the context were strongly biased. Though the ambiguous words employed in the present study did not have one meaning which was clearly less frequent, second meanings were always of a slightly lower frequency than first meanings. Even the existence of a slightly less frequent meaning could have rendered nonfluent aphasic subjects less sensitive to second-meaning biased contexts and led to their failure to activate any meanings in this context.

Proposing that nonfluent aphasic patients were differentially sensitive to the type of biasing context does leave open the possibility that sentences in the biased conditions somehow differed from each other, perhaps in terms of complexity or in the strength of their bias. Each of these possibilities is discussed below and ruled out on a number of grounds. First, differences in the structure or complexity of the sentences cannot account for the present findings. The ambiguous words were embedded in the same clause in all three contexts (i.e., only information in the initial clause was manipulated). In addition, all sentences were of a comparable length and contained a similar number of syntactic constituents occurring in the same order, thus no apparent differences in syntactic complexity existed. The possibility that sentences in second-meaning biased contexts were less biased and thus provided fewer contextual constraints for the patients can also be rejected based on the fact that a pretest of the materials used in this study indicated that sentences in the two conditions were comparably biased. Thus, it appears that differences in sentence complexity and in the strength of the bias provided by the sentences cannot account for nonfluent aphasic patients' lack of activation in second-meaning biased contexts and that this result reflects a genuine insensitivity to this particular context. Though the data herein have thus far been argued to support a deficit in context use, the fact that activation was absent for the nonfluent aphasic patients at the long ISI cannot be explained with reference only to a deficit of this sort; this finding also implicates a disturbance of the time course of activation of ambiguous word meanings.

Disruptions of the time course of lexical activation have been thought to underlie a number of nonfluent aphasic patients' sentence comprehension deficits (Prather et al., 1992, 1994, 1997; Swinney et al., 1989, 2000). The picture that emerges from these studies is that their primary disturbance is related to the speed of activation, in that it is 'slowed' relative to age-matched individuals without brain damage. In support of this position, some studies have shown that nonfluent Broca's aphasic patients only exhibit consistent semantic priming effects starting at ISIs of $1500 \mathrm{~ms}$, and not at shorter ISIs of 500, 800 and $1100 \mathrm{~ms}$ (Prather et al., 1992, 1997). One drawback of these studies, though, is that they have only used word priming paradigms. As a result, when we consider the 'slowed activation' account in light of online sentence priming studies of ambiguity resolution, including the present study, several issues are raised. In these studies, nonfluent aphasic patients have been shown to prime at very brief ISIs $(0-100 \mathrm{~ms})$, ignoring for now differences in whether the dominant meaning or both meanings were primed (Hagoort, 1990; Swinney et al., 1989). This finding seems to run counter to an account that proposes that activation is slowed. In Swinney et al. (1989), rather than assuming the spread of activation between related concepts is slowed, it was hypothesized that lexical access (i.e., the lexical search module) is slowed, such that only dominant meanings can be retrieved and sufficiently activated within a short time frame. Clearly, this argument introduces a distinction between access to meanings being slowed versus the spread of activation being slowed (presumably after the meanings have already been accessed). In a later study, Prather et al. (1997) frame Swinney et al.'s (1989) results more in terms of the spread of activation, arguing that Broca's aphasic patients only activated the dominant probe within a short time frame because it was more closely linked to the dominant meaning than the subordinate probe. In other words, because activation was slowed, it could only propagate to the dominant probe and not to the more distant subordinate probe. Thus, it appears that the dominant meaning can be activated despite the fact that the spread of activation is slowed.

While the 'slowed activation' view seems to provide an explanation of the above results, it still fails to account for the finding that nonfluent aphasic patients in the present study were able to activate both meanings at 
the short ISI (see also Hagoort, 1990; Swaab et al., 1998). Clearly, activation cannot be slowed if both meanings are available initially. In fact, if activation were indeed slowed, it should also be the case that one or more meanings are activated at longer ISIs, a finding that is also inconsistent with the present results. What the lack of activation observed at the $750 \mathrm{~ms}$ ISI in this study suggests is a disruption of a different nature, namely that nonfluent aphasic patients experience a faster than normal decay of activation (see Haarmann \& Kolk, 1994; Kolk, 1995; Kolk \& Van Grunsven, 1985 for a similar proposal related to the activation of syntactic information). It seems that both meanings are made available for a brief period of time (i.e., activation is initially 'normal'), but that soon after this period, activation rapidly decays. That activation can decay at a rapid rate is not unheard of, especially with respect to ambiguous word meanings. There is evidence that neurologically intact individuals' selection of contextually appropriate meanings occurs within $250 \mathrm{~ms}$, indicating that activation for a particular meaning can rapidly decay, provided that meaning cannot be integrated into context (Simpson, 1984). Because nonfluent aphasic patients are unable to integrate meanings into context, it is not surprising that activation for these meanings decays within a relatively short period of time. One final point, raised by the results of Prather et al. $(1992,1997)$, concerns the possibility that activation does again build up after it has decayed, only at a much slower rate. If this were indeed the case, then it would explain why Prather et al. $(1992,1997)$ only found activation with an ISI of $1500 \mathrm{~ms}$. Results of the present study do not rule out this possibility and clearly show that activation had not built up again by $750 \mathrm{~ms}$. It remains to be seen whether nonfluent aphasic patients would have reactivated ambiguous word meanings and whether context would have come into play at an even longer ISI.

\subsection{Context insensitivity and frequency-based lexical activation in RHD individuals}

At both the short and long ISIs, RHD individuals were expected to activate both meanings of the ambiguous words regardless of context, if, as argued, they have a deficit in inferring which meaning is appropriate to the context (i.e., a deficit in context use). Contrary to this prediction, RHD individuals in the present study only activated first meanings in unbiased contexts at the short ISI, though a similar trend was found in secondmeaning biased contexts. Moreover, at the long ISI, they again only activated first meanings in unbiased contexts, but also showed a trend toward activation of the contextually appropriate meaning in second-meaning biased contexts. As such, results at the short ISI are consistent with the hypothesis that these individuals are unable to initially use context to complete the process of ambiguity resolution. They also suggest that RHD individuals may rely on meaning frequency to activate ambiguous word meanings. Results at the long ISI are less conclusive, in that RHD individuals appeared to be influenced by context, but only in second-meaning biased contexts. Overall, the present results provide some support for the 'context deficit' hypothesis. In addition, they argue against other proposals, such as the 'sustained activation' account, according to which RHD individuals should have experienced prolonged interference from inappropriate meanings of ambiguous words as a result of their impaired ability to suppress these meanings (Tompkins et al., 1997, 2000).

Though results of the present experiment diverge from those of previous studies, they do arrive at the same conclusion, namely that RHD individuals have difficulty in resolving lexically ambiguous words in context. It is the source of their deficit which still remains unclear. While some studies have attributed RHD individuals' difficulty in resolving ambiguous words to an inability to suppress or inhibit inappropriate meanings (Tompkins et al., 1997, 2000), the present research attributes their deficit to an inability to use context. In this study, RHD individuals only showed evidence of activation in unbiased contexts, though trends toward activation of inappropriate meanings at the short ISI and of appropriate meanings at the long ISI were observed in second-meaning biased contexts. In their study, Tompkins et al. (2000) address the claim that an inability to suppress inappropriate meanings could also be due to a deficit in determining what is contextually appropriate (i.e., a deficit in context use). In addition to including experimental trials where a probe word was related to the unbiased meaning of a sentence (as mentioned in the introduction), they included another set of trials, in which probe words were related to the biased meaning of the sentence. Because both control and RHD subjects were more accurate in accepting probe words (e.g., tool) after biased sentences (e.g., She sharpened the DRILL) than after sentences which did not provide any bias (e.g., She started the DRILL), Tompkins et al. (2000) ruled out the possibility that RHD individuals were unable to use the context. The authors do, however, leave open the possibility that with lengthier and more complex materials, RHD individuals may have an increased difficulty in appreciating what is contextually appropriate. Because the sentences employed in the present study were of a more complex nature than those used by Tompkins et al. (2000), RHD individuals may have had much greater difficulty in using these sentence contexts to resolve ambiguity.

A somewhat surprising result of the present study was that RHD individuals activated first meanings in an unbiased context, whereas control subjects did not activate any meanings in this same context. Recall that control subjects, in failing to select the appropriate 
meaning based on either context or meaning frequency, were argued to be unable to sufficiently activate one or both meanings. The obvious question that arises is why were RHD individuals able to activate first meanings in this context. One explanation hinges on a crucial difference between the two groups, namely that RHD individuals were not using the context, whereas control subjects did attempt to use the context to determine whether a particular meaning was appropriate. Without the use of context, RHD individuals would be left to use meaning frequency to resolve ambiguity (not only in unbiased contexts, but in the biased contexts as well). As such, this greater reliance on frequency would perhaps make RHD individuals more sensitive to differences in the frequency of the ambiguous word's meanings. This could then account for why they only activated first meanings in unbiased contexts, as these meanings were always of a slightly higher frequency. Crucially, there is further support for this proposal, though only a trend, in second-meaning biased contexts, where RHD individuals again only activated first meanings at the short ISI. Thus, it seems that an inability to use context drove RHD subjects to resolve ambiguity based solely on frequency (at least at the short ISI). It should be noted that the findings at the short ISI are also consistent with an activation deficit, specifically a deficit in activating second meanings. However, given that no known activation deficits have been reported in the literature on RHD individuals, and that successful ambiguity resolution requires the use of context, the explanation offered here seems more likely. In addition, it should be noted that the arguments outlined here are only speculative at this point in time and require further empirical validation.

Another finding of interest was RHD individuals' apparent use of context in second-meaning biased contexts at the long ISI. Though only a trend, this result remains somewhat curious given that at the short ISI, these individuals did not appear to be influenced by context and activated contextually inappropriate meanings in second-meaning biased contexts. There is some evidence in the literature that RHD individuals are able to use contextual information under certain conditions. For instance, RHD individuals have been shown to use context in resolving ambiguous pronouns in single sentence and minimal discourse (i.e., two-sentence) contexts (Leonard, Waters, \& Caplan, 1997a, 1997b). Moreover, they also appear to be sensitive to the semantic integrity of sentences, when monitoring for words in normal versus semantically anomalous sentences (Leonard \& Baum, 1998). To account for these results, it has been argued that RHD individuals can use contextual information in tasks that promote more automatic processing (i.e., when processing demands are reduced). While this explanation is empirically supported, it cannot, however, account for the present re- sults, as contexts effects were only observed at the long ISI, a point at which controlled processing, and not automatic processing, is assumed to be at play. Support for context use by RHD individuals in the present study is therefore extremely limited. That they appeared to be using the context also cannot be explained with reference to any current proposals in the literature. Further research is obviously needed to determine the exact conditions under which context effects emerge in RHD individuals, especially with respect to lexical ambiguity resolution.

\subsection{Hemispheric contributions to lexical ambiguity res- olution}

In addition to furthering our knowledge of the extent to which brain damage disrupts certain aspects of language comprehension, the present research also speaks to the issue of how the individual hemispheres contribute to language comprehension, and in particular to ambiguity resolution. Two conclusions can be drawn with respect to contributions of the cerebral hemispheres to the resolution process. First, ambiguity resolution is not carried out solely by one hemisphere, as indicated by the finding that damage to either the $\mathrm{LH}$ or $\mathrm{RH}$ produces a deficit in processing ambiguous words in context. In neither case is the intact hemisphere able to perform ambiguity resolution alone, assuming that damage to one hemisphere does result in "unopposed" functioning of the intact hemisphere (Chiarello, 1998, p. 146). For the RH, this is not surprising, given that it has been purported to maintain alternative, even contextually inappropriate, meanings. Thus, if processing could only be carried out by this hemisphere, ambiguity resolution should not be successful (in LHD individuals). For the $\mathrm{LH}$, this is somewhat surprising, given that selection appears to be one of its main functions. If processing could only be carried out by this hemisphere, ambiguity resolution should be successful (in RHD individuals). In other words, the intact $\mathrm{LH}$ should be sufficient to resolve ambiguity, though the present findings would suggest otherwise. This discrepancy once again points out that mapping conclusions obtained from studies of brain-damaged populations onto those derived from studies of normal hemispheric processing is not clear-cut. Though both hemispheres deal with different aspects of lexical ambiguity resolution, clearly the functions they perform are not independent, nor by themselves sufficient. It therefore seems that both hemispheres contribute to the resolution process, each performing unique, but complementary functions (Faust \& Chiarello, 1998b; Faust \& Gernsbacher, 1996).

While it has been argued that both hemispheres are needed to resolve ambiguity, a further argument can be made that each hemisphere must use contextual information to a certain extent. The fact that the LHD and 
RHD patient groups in the present study were not highly influenced by a biasing context supports the position that sensitivity to context cannot be localized to one hemisphere. This proposal may at first seem to run counter to claims arguing for a LH superiority in sentence comprehension. This is based on the finding that only the LH is able to combine syntactic, semantic and pragmatic information to build a conceptual representation of the meaning of a sentence, that is, to process a sentence at the message level (Faust, 1998; Faust \& Chiarello, 1998a; Faust \& Kravetz, 1998; Faust, Kravetz, \& Babkoff, 1993). Through sensitivity to message-level constraints, the LH could use contextual information to decide which meaning of an ambiguous word is appropriate. This message-level processing seems to be what was disrupted in the present study, therefore it may not only be a function of the $\mathrm{LH}$, but also of the RH (for a similar argument, see Chiarello, Liu, \& Faust, 2001). Alternatively, it could be argued that a second type of processing was also disrupted, one that is unique to the RH. This possibility is suggested by the results of a number of studies, which have shown that the $\mathrm{RH}$ is able to process a sentence at the word level. As such, the RH is able to analyze the semantic relations between the individual words in the sentence (Beeman et al., 1994; Faust, 1998; Faust, Babkoff, \& Kravetz, 1995). Thus, if a sentence were to contain one or more words semantically related to the target, this would then provide a way for the $\mathrm{RH}$ to determine which meaning of an ambiguous word was appropriate. In sum, the present research suggests that both hemispheres make use of information from context, potentially through the use of different processing strategies.

\section{Conclusion}

The present research demonstrates that deficits in resolving ambiguous words in context are exhibited subsequent to both $\mathrm{LH}$ and RH damage. Though results of the two patient groups differed somewhat, the nature of the deficits in both cases seems to center around difficulties in using information from context. LH damage seems to impair the ability to initially integrate meanings into context, while also producing a faster than normal decay of lexical activation. RH damage also seems to impair initial access to contextual information, while also leading to a reliance on frequencybased lexical activation. Overall, the present results lend support to the hypothesis that in order to successfully complete ambiguity resolution, both hemispheres require access to contextual information. Moreover, they further highlight the importance of the two hemispheres working in concert as an integral part of the resolution process. It should be noted that the deficits observed in the present study are restricted to the use of local (i.e., single-sentence) contextual information; therefore, caution must be taken in generalizing these results to other types of contexts. Further research is required to determine the extent of brain-damaged patients' deficits in context use. In particular, the ability of LHD and RHD individuals to use larger discourse contexts (i.e., two or more sentences) to resolve lexically ambiguous words remains an important area for future investigation.

\section{References}

Atchley, R. A., Burgess, C., Audet, C., \& Arambel, S. (1996). Timecourse, context effects and the processing of lexical ambiguity in the cerebral hemispheres. Brain and Cognition, 30, 277-280.

Atchley, R. A., Keeney, M., \& Burgess, C. (1999). Cerebral hemispheric mechanisms linking ambiguous word meaning retrieval and creativity. Brain and Cognition, 40, 479-499.

Beeman, M. J. (1993). Semantic processing in the right hemisphere may contribute to drawing inferences from discourse. Brain and Language, 44, 80-120.

Beeman, M. J. (1998). Coarse semantic coding and discourse comprehension. In M. J. Beeman, \& C. Chiarello (Eds.), Right hemisphere language comprehension: Perspectives from cognitive neuroscience (pp. 255-284). Mahwah, NJ: Lawrence Erlbaum Associates.

Beeman, M. J., Friedman, R. B., Grafman, J., Perez, E., Diamond, S., $\&$ Lindsay, M. B. (1994). Summation priming and coarse semantic coding in the right hemisphere. Journal of Cognitive Neuroscience, 6, 26-45.

Bihrle, A. M., Brownell, H. H., Powelson, J., \& Gardner, H. (1986). Comprehension of humorous and nonhumorous materials by brain-damaged patients. Brain and Cognition, 5, 399-411.

Binder, K. S., \& Morris, R. K. (1995). Eye movements and lexical ambiguity resolution: Effects of prior encounter and discourse topic. Journal of Experimental Psychology: Learning, Memory and Cognition, 21, 1186-1196.

Binder, K. S., \& Rayner, K. (1998). Contextual strength does not modulate the subordinate bias effect: Evidence from eye fixations and self-paced reading. Psychonomic Bulletin and Review, 5, 271276.

Brownell, H. H., Potter, H. H., Bihrle, A. M., \& Gardner, H. (1986). Inference deficits in right brain-damaged patients. Brain and Language, 27, 310-321.

Brownell, H. H., Potter, H. H., Michelow, D., \& Gardner, H. (1984). Sensitivity to lexical denotation and connotation in brain-damaged patients: A double dissociation? Brain and Language, 22, 253-265.

Brownell, H. H., Simpson, T. L., Bihrle, A. M., Potter, H. H., \& Gardner, H. (1990). Appreciation of metaphoric alternative word meanings by left and right brain-damaged patients. Neuropsychologia, 28, 375-383.

Burgess, C., \& Simpson, G. B. (1988). Cerebral hemispheric mechanisms in the retrieval of ambiguous word meanings. Brain and Language, 33, 86-103.

Caplan, D. (1992). Language: Structure, process and disorders. Cambridge, MA: MIT Press.

Chiarello, C. (1998). On codes of meaning and the meaning of codes: Semantic access and retrieval within and between hemispheres. In M. J. Beeman, \& C. Chiarello (Eds.), Right hemisphere language comprehension: Perspectives from cognitive neuroscience (pp. 141160). Mahwah, NJ: Lawrence Erlbaum Associates.

Chiarello, C., Liu, S., \& Faust, M. (2001). Bihemispheric sensitivity to sentence anomaly. Neuropsychologia, 39, 1451-1463.

Collins, M. (2002). Interhemispheric communication via direct connections for alternative meanings of ambiguous words. Brain and Language, 80, 77-96. 
Coney, J., \& Evans, K. D. (2000). Hemispheric asymmetries in the resolution of lexical ambiguity. Neuropsychologia, 38, 272-282.

Cook, N. D. (1989). Toward a central dogma for psychology. New Ideas in Psychology, 7, 1-18.

Cook, N. D., \& Beech, A. R. (1990). The cerebral hemispheres and bilateral neural nets. International Journal of Neuroscience, 52, 201210.

Dopkins, S., Morris, R. K., \& Rayner, K. (1992). Lexical ambiguity and eye fixations in reading: A test of competing models of lexical ambiguity resolution. Journal of Memory and Language, 31, 461-476.

Duffy, S. A., Morris, R. K., \& Rayner, K. (1988). Lexical ambiguity and fixation times in reading. Journal of Memory and Language, 27, 429-446.

Fassbinder, W., \& Tompkins, C. A. (2001). Slowed lexical-semantic activation in individuals with right hemisphere brain damage? Aphasiology, 15, 1079-1090.

Faust, M. (1998). Obtaining evidence of language comprehension from sentence priming. In M. J. Beeman, \& C. Chiarello (Eds.), Right hemisphere language comprehension: Perspectives from cognitive neuroscience (pp. 161-185). Mahwah, NJ: Lawrence Erlbaum Associates.

Faust, M., Babkoff, H., \& Kravetz, S. (1995). Linguistic processes in the two cerebral hemispheres: Implications for modularity vs. interactionism. Journal of Clinical and Experimental Neuropsychology, 17, 171-192.

Faust, M., \& Chiarello, C. (1998a). Constraints on sentence priming in the cerebral hemispheres: Effects of intervening words in sentences and lists. Brain and Language, 63, 219-236.

Faust, M., \& Chiarello, C. (1998b). Sentence context and lexical ambiguity resolution by the two hemispheres. Neuropsychologia, $36,827-835$.

Faust, M., \& Kravetz, S. (1998). Levels of sentence constraint and lexical decision in the two hemispheres. Brain and Language, 62, 149-162.

Faust, M., Kravetz, S., \& Babkoff, H. (1993). Hemisphericity and topdown processing of language. Brain and Language, 44, 1-18.

Faust, M. E., \& Gernsbacher, M. A. (1996). Cerebral mechanisms for suppression of inappropriate information during sentence comprehension. Brain and Language, 53, 234-259.

Folstein, M. F., Folstein, S. E., \& McHugh, P. R. (1975). "Minimental state": A practical method for grading the cognitive state of patients for the clinician. Journal of Psychiatric Research, 12, 189198.

Francis, W., \& Kucera, H. (1982). Frequency analysis of English usage. Boston, MA: Houghton Mifflin.

Gardner, H., Brownell, H. H., Wapner, W., \& Michelow, D. (1983). Missing the point: The role of the right hemisphere in processing complex linguistic materials. In E. Perecman (Ed.), Cognitive processing in the right hemisphere (pp. 169-191). New York: Academic Press.

Goodglass, H., \& Kaplan, E. (1983). The assessment of aphasia and related disorders. Philadelphia, PA: Lea and Febiger.

Haarmann, H. J., \& Kolk, H. H. (1994). On-line sensitivity to subjectverb agreement violations in Broca's aphasics: The role of syntactic complexity and time. Brain and Language, 46, 493-516.

Hagoort, P. (1990). Tracking the time course of language understanding in aphasia. Ph.D. dissertation, University of Nijmegen, The Netherlands.

Hasbrooke, R. E., \& Chiarello, C. (1998). Bihemispheric processing of redundant bilateral lexical information. Neuropsychology, 12, 78-94.

Joanette, Y., Goulet, P., \& Hannequin, D. (1990). Right hemisphere and verbal communication. New York: Springer.

Kaplan, E., Goodglass, H., \& Weintraub, S. (1983). Boston naming test. Philadelphia, PA: Lea and Febiger.

Kolk, H. H. (1995). A time-based approach to agrammatic production. Brain and Language, 50, 282-303.
Kolk, H. H., \& Van Grunsven, M. M. (1985). Agrammatism as a variable phenomenon. Cognitive Neuropsychology, 2, 347-384.

Lehman, M. T., \& Tompkins, C. A. (2000). Inferencing in adults with right hemisphere brain damage: An analysis of conflicting results. Aphasiology, 14, 485-499.

Leonard, C. L., \& Baum, S. R. (1998). On-line evidence for context use by right-brain-damaged patients. Journal of Cognitive Neuroscience, 10, 499-508.

Leonard, C. L., Waters, G. S., \& Caplan, D. (1997a). The use of contextual information by right brain-damaged individuals in the resolution of ambiguous pronouns. Brain and Language, 57, 309342.

Leonard, C. L., Waters, G. S., \& Caplan, D. (1997b). The use of contextual information related to general world knowledge by right brain-damaged individuals in pronoun resolution. Brain and Language, 57, 343-359.

Martin, C., Vu, H., Kellas, G., \& Metcalf, K. (1999). Strength of discourse context as a determinant of the subordinate bias effect. Quarterly Journal of Experimental Psychology, 52 A, 813-839.

Mertus, J. (2000). Brown lab interactive speech system /Computer software]. Providence, RI: Brown University.

Milberg, W., Blumstein, S. E., \& Dworetzky, B. (1987). Processing of lexical ambiguities in aphasia. Brain and Language, 31, 138-150.

Paul, S. T., Kellas, G., Martin, M., \& Clark, M. B. (1992). Influence of contextual features on the activation of ambiguous word meanings. Journal of Experimental Psychology: Learning, Memory and Cognition, 18, 703-717.

Prather, P. A., Love, T., Finkel, L., \& Zurif, E. (1994). Effects of slowed processing on lexical activation: Automaticity without encapsulation. Brain and Language, 47, 326-329.

Prather, P. A., Zurif, E., Love, T., \& Brownell, H. H. (1997). Speed of lexical activation in nonfluent Broca's aphasia and fluent Wernicke's aphasia. Brain and Language, 59, 391-411.

Prather, P. A., Zurif, E., Stern, C., \& Rosen, T. J. (1992). Slowed lexical access in nonfluent aphasia: A case study. Brain and Language, 43, 336-348.

Rayner, K., \& Duffy, S. A. (1986). Lexical complexity and fixation times in reading: Effects of word frequency, verb complexity, and lexical ambiguity. Memory and Cognition, 14, 191-201.

Rayner, K., \& Frazier, L. (1989). Selection mechanisms in reading lexically ambiguous words. Journal of Experimental Psychology: Learning, Memory and Cognition, 15, 779-790.

Rayner, K., Pacht, J. M., \& Duffy, S. A. (1994). Effects of prior encounter and global discourse bias on the processing of lexically ambiguous words: Evidence from eye fixations. Journal of Memory and Language, 33, 527-544.

Rodel, M., Cook, N. D., Regard, M., \& Landis, T. (1992). Hemispheric dissociation in judging semantic relations: Complementarity for close and distant associates. Brain and Language, 43, 448-459.

Sereno, S. C. (1995). Resolution of lexical ambiguity: Evidence from an eye movement priming paradigm. Journal of Experimental Psychology: Learning, Memory and Cognition, 21, 582-595.

Simpson, G. B. (1981). Meaning dominance and semantic context in the processing of lexical ambiguity. Journal of Verbal Learning and Verbal Behavior, 20, 120-136.

Simpson, G. B. (1984). Lexical ambiguity and its role in models of word recognition. Psychological Bulletin, 96, 316-340.

Simpson, G. B. (1994). Context and the processing of ambiguous words. In M. A. Gernsbacher (Ed.), Handbook of psycholinguistics (pp. 359-374). New York: Academic Press.

Simpson, G. B., \& Krueger, M. A. (1991). Selective access of homograph meanings in sentence context. Journal of Memory and Language, 30, 627-643.

Stevens, J. (1996). Applied multivariate statistics for the social sciences (3rd ed.). Mahwah, NJ: Lawrence Erlbaum Associates. 
Swaab, T. Y., Brown, C. M., \& Hagoort, P. (1998). Understanding ambiguous words in sentence contexts: Electrophysiological evidence for delayed contextual selection in Broca's aphasia. Neuropsychologia, 36, 737-761.

Swinney, D. A., Prather, P. A., \& Love, T. (2000). The time-course of lexical access and the role of context: Converging evidence from normal and aphasic processing. In Y. Grodzinsky, L. Shapiro, \& D. A. Swinney (Eds.), Language and the brain: Representation and processing (pp. 273-292). San Diego: Academic Press.

Swinney, D. A., Zurif, E., \& Nicol, J. L. (1989). The effects of focal brain damage on sentence processing: An examination of the neurological organization of a mental module. Journal of Cognitive Neuroscience, 1, 25-37.

Tabossi, P. (1988). Accessing lexical ambiguity in different types of sentential contexts. Journal of Memory and Language, 27, 324 340 .

Tabossi, P., Colombo, L., \& Job, R. (1987). Accessing lexical ambiguity: Effects of context and dominance. Psychological Research, 49, 161-167.

Titone, D. A. (1998). Hemispheric differences in context sensitivity during lexical ambiguity resolution. Brain and Language, 65, 361394.

Tompkins, C. A., Baumgaertner, A., Lehman, M. T., \& Fassbinder, W. (2000). Mechanisms of discourse comprehension impairment after right hemisphere brain damage: Suppression in lexical ambiguity resolution. Journal of Speech, Language and Hearing Research, 43, 62-78.

Tompkins, C. A., Baumgaertner, A., Lehman, M. T., \& Fossett, T. R. D. (1997). Suppression and discourse comprehension in right brain-damaged adults: A preliminary report. Aphasiology, 11, 505519.

Tompkins, C. A., Lehman, M. T., \& Baumgaertner, A. (1999). Suppression and inference revision in right brain-damaged and non-brain-damaged adults. Aphasiology, 13, 725-742.

Twilley, L. C., Dixon, P., Taylor, D., \& Clark, K. (1994). University of Alberta norms of relative meaning frequency for 566 homographs. Memory and Cognition, 22, 111-126.

Van Lancker, D. R., \& Kempler, D. (1987). Comprehension of familiar phrases by left- but not by right-hemisphere damaged patients. Brain and Language, 32, 265-277.

Van Petten, C., \& Kutas, M. (1987). Ambiguous words in context: An event-related potential analysis of the time course of meaning activation. Journal of Memory and Language, 26, 188-208.

Vu, H., Kellas, G., Metcalf, K., \& Herman, R. (2000). The influence of global discourse on lexical ambiguity resolution. Memory and Cognition, 28, 236-252.

Vu, H., Kellas, G., \& Paul, S. T. (1998). Sources of sentence constraint on lexical ambiguity resolution. Memory and Cognition, 26, 979-1001.

Wechsler, D. W. (1987). Wechsler memory scale-revised. San Antonio: Harcourt, Brace and Jovanovich.

Weylman, S., Brownell, H. H., Roman, M., \& Gardner, H. (1989). Appreciation of indirect requests by left- and right-brain-damaged patients: The effects of verbal context and conventionality of wording. Brain and Language, 36, 580-591.

Wiig, E. H., \& Secord, W. A. (1989). Test of language competenceexpanded edition. San Antonio: Harcourt, Brace and Jovanovich.

Wilson, B., Cockburn, J., \& Halligan, P. (1987). Behavioural inattention test. Titchfield, UK: Thames Valley Test Company. 